(C) The Author(s), 2021. Published by Cambridge University Press on behalf of The Nutrition Society. This is an Open Access article, distributed under the terms of the Creative Commons Attribution licence (http://creativecommons.org/licenses/by/4.0/), which permits unrestricted re-use, distribution, and reproduction in any medium, provided the original work is properly cited.

\title{
Mechanistic aspects of carotenoid health benefits - where are we now?
}

Torsten Bohn ${ }^{1 * \dagger}$, M. Luisa Bonet ${ }^{2 \dagger}$, Patrick Borel ${ }^{3 \dagger}$, Jaap Keijer ${ }^{4 \dagger}$, Jean-Francois Landrier ${ }^{3 \dagger}$, Irina Milisav ${ }^{5,6 \dagger}$, Joan Ribot $^{2 \dagger}$, Patrizia Riso ${ }^{\dagger \dagger}$, Brigitte Winklhofer-Roob ${ }^{8 \dagger}$, Yoav Sharoni ${ }^{\dagger \dagger}$, Joana Corte-Real ${ }^{1}$, Yvonne van Helden ${ }^{4}$, Monica Rosa Loizzo ${ }^{10}$, Borut Poljšak ${ }^{5}$, Marisa Porrini ${ }^{7}$, Johannes Roob ${ }^{11}$, Polonca Trebše ${ }^{5}$, Rosa Tundis ${ }^{10}$, Agata Wawrzyniak ${ }^{12}$ (i) , Ralph Rühl ${ }^{13 * \dagger}$ and Joanna Dulińska-Litewka ${ }^{14 * \dagger}$ (1)

${ }^{1}$ Luxembourg Institute of Health, Population Health Department, Nutrition and Health Research Group, 1 A-B, rue Thomas Edison, L-1445 Strassen, Luxembourg

${ }^{2}$ Laboratory of Molecular Biology, Nutrition and Biotechnology, Universitat de les Illes Balears and CIBER fisiopatología de la Obesidad y Nutrición, Cra. Valldemossa, km 7.5, 07122 Palma de Mallorca, Spain

${ }^{3}$ Aix Marseille Univ, INRAe, INSERM, C2VN, Marseille, France

${ }^{4}$ Wagenigen University, PO box 338, De Elst 1, 6700 AH Wageningen, The Netherlands

${ }^{5}$ University of Ljubljana, Faculty of Health Sciences, Zdravstvena pot 5, 1000 Ljubljana, Slovenia

${ }^{6}$ University of Ljubljana, Faculty of Medicine, Inst. of Pathophysiology, Zaloska 4, 1000 Ljubljana, Slovenia

${ }^{7}$ Department of Food, Environmental and Nutritional Sciences, Division of Human Nutrition, Università degli Studi di Milano, Milano, Italy

${ }^{8}$ Human Nutrition \& Metabolism Research and Training Center, Institute of Molecular Biosciences, Karl-Franzens University, Graz, Austria

${ }^{9}$ Department of Clinical Biochemistry, Faculty of Health Sciences, Ben-Gurion University of the Negev, P.O. Box 653, Beer Sheva, Israel

${ }^{10}$ Department Pharmacy, Health and Nutritional Sciences, University of Calabria, Calabria, Italy

${ }^{11}$ Research Unit Chronic Inflammation in Nephrology, Clinical Division of Nephrology, Department of Internal Medicine, Medical University, Graz, Austria

${ }^{12}$ Institute of Human Nutrition Sciences, Warsaw University of Life Sciences (WULS-SGGW), Nowoursynowska St. 159C, 02-776 Warsaw, Poland

${ }^{13}$ Paprika Bioanalytics BT, Debrecen, Hungary

${ }^{14}$ Chair of Medical Biochemistry, Jagiellonian University, Medical College, Kopernika 7, 31-034 Krakow, Poland

\section{Abstract}

Dietary intake and tissue levels of carotenoids have been associated with a reduced risk of several chronic diseases, including cardiovascular diseases, type 2 diabetes, obesity, brain-related diseases and some types of cancer. However, intervention trials with isolated carotenoid supplements have mostly failed to confirm the postulated health benefits. It has thereby been speculated that dosing, matrix and synergistic effects, as well as underlying health and the individual nutritional status plus genetic background do play a role. It appears that our knowledge on carotenoid-mediated health benefits may still be incomplete, as the underlying mechanisms of action are poorly understood in relation to human relevance. Antioxidant mechanisms - direct or via transcription factors such as NRF2 and NF-KB - and activation of nuclear hormone receptor pathways such as of RAR, RXR or also PPARs, via carotenoid metabolites, are the basic principles which we try to connect with carotenoidtransmitted health benefits as exemplified with described common diseases including obesity/diabetes and cancer. Depending on the targeted diseases, single or multiple mechanisms of actions may play a role. In this review and position paper, we try to highlight our present knowledge on carotenoid metabolism and mechanisms translatable into health benefits related to several chronic diseases.

Key words: Antioxidants: Apo-carotenoids: Carotenoid metabolites: Chronic diseases: Nuclear hormone receptors: PPAR: RXR: RAR: Transcription factors

(Received 10 December 2020; revised 17 May 2021; accepted 25 May 2021; accepted manuscript published online 31 May 2021)

* Corresponding authors: Joanna Dulińska-Litewka, email joanna.dulinska-litewka@uj.edu.pl; Torsten Bohn, email Torsten.Bohn@lih.lu; Ralph Rühl, email Ralphruehl@web.de

This review article is dedicated in memoriam to Johannes Roob ( +2 July 2019), a fantastic person and our dear EUROCAROTEN friend.

$\uparrow$ These authors are the section heads and contributed major parts of this review article. 

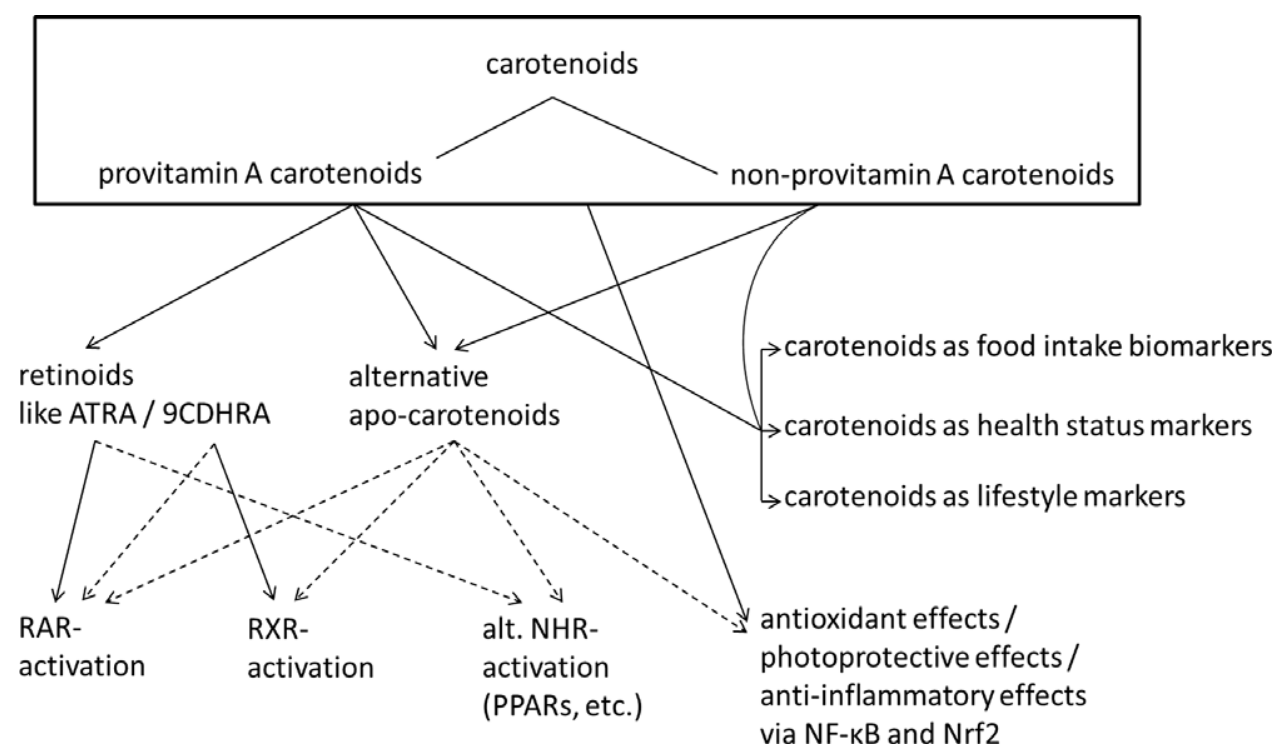

Fig. 1. Summary of carotenoid mediated health effects. Suggested and not conclusively proven connections are indicated with dashed lines. Abbreviations: ATRA, all-trans retinoic acid; 9CDHRA, 9-cis-13,14-dihydroretinoic acid; RAR, retinoic acid receptor; RXR, retinoid X receptor; NHR, nuclear hormone receptor; alt., alternative; PPARs, peroxisome proliferator-activated receptor.

\section{Introduction}

Carotenoids are typically C-40 based tetraterpenoid secondary plant compounds, although more recently, also C-30 ${ }^{(1)}$ and $\mathrm{C}-50^{(2)}$ based carotenoids in bacteria have been described, resulting in over 1100 known carotenoids ${ }^{(3)}$. Carotenoids do occur in plants, bacteria, fungi and animals, though the latter are generally unable to produce them, most likely due to evolutionary loss of functional genes encoding the necessary enzymes for biosynthesis. Many carotenoids are pigments of yellow or orange colour and are associated in plants with chlorophyll, improving the photosynthesis process by enhancing light harvesting in the blue spectrum and protecting from photooxidative damage ${ }^{(4)}$.

Carotenoids have been met with much interest, due to the association of their dietary intake as well as circulating blood concentrations with reduced incidence of chronic diseases. For example, subjects with the highest concentrations of circulating $\beta$-carotene showed decreased all-cause mortality compared with those with lowest concentrations ${ }^{(5)}$. In a recent meta-analysis, both dietary intake of various carotenoids ( $\beta$-carotene, $\alpha$-carotene and $\beta$-cryptoxanthin) and circulating concentrations in the blood were related to decreased total mortality ${ }^{(6)}$. Based on these assumed health benefits, a health index has been proposed, with plasma/serum concentrations below $1 \mu \mathrm{M}$ of total carotenoids being related to a significantly increased risk for chronic diseases ${ }^{(7)}$. These mainly correlationbased studies indicate beneficial effects for high physiological levels of carotenoids and, in consequence, support a recommendation for a high intake of fruits and vegetables rich in carotenoids (reviewed in ref. ${ }^{(8)}$ ). Besides carotenoids, a high intake of fruits and vegetables is also associated with a healthier lifestyle, including regular exercise, less smoking and less alcohol abuse ${ }^{(9)}$, as well as generally healthier food intake, including a lower intake of processed meat ${ }^{(10)}$. Furthermore, lower endogenous carotenoid levels were also described to correlate with an increased chronic inflammatory status and may simply function as a health status biomarker, not only due to a lower intake of fruits and vegetables but also because of a higher degradation of carotenoids due to a chronic pro-inflammatory environment ${ }^{(11,12)}$. Consequently, higher physiological carotenoid levels in humans could simply function as biomarker of a healthier lifestyle, a higher intake of fruits and vegetables and a better health status $^{(9)}$, as indicated in Fig. 1. Despite these positive associations, also negative effects have been reported, i.e. increased risk for lung cancer in smokers upon administering high doses of supplemental $\beta$-carotene $(20-30 \mathrm{mg} / \mathrm{d}$ ) for several years $^{(13,14)}$.

Carotenoids have been associated with the prevention and amelioration of chronic diseases in several ways. In addition to acting as mere indicators of a diet rich in plant-based foods ${ }^{(15)}$ and, thus, healthy eating patterns, several carotenoids, i.e. those with provitamin A potential, can act as essential micronutrients. These include $\alpha$-carotene, $\beta$-carotene and $\beta$-cryptoxanthin, which can be converted by $\beta$-carotene oxygenase 1 (BCO1) in the human body into vitamin A active compounds, important for subjects with low intake of preformed vitamin A, i.e. mainly retinyl esters, such as vegetarians or in more rural non-Westernised societies with low meat or animal-based food intake ${ }^{(16)}$. Thus, regular provitamin A carotenoid intake by such people contributes to the prevention of vitamin A deficiency, which is indicated by serum levels of retinol less then $0.7 \mu \mathrm{M}^{(17)}$. Night blindness and xerophthalmia are vitamin A deficiency syndromes ${ }^{(18)}$, though mainly of relevance in developing countries with co-occurring additional nutrient deficiencies ${ }^{(19,20)}$, while abnormalities such as a reduced immunological competence and pulmonological disturbances are more frequent vitamin A deficiency disorders in humans with main relevance for children in Western society $^{(21,22)}$. 
Rather specifically, the carotenoids lutein and zeaxanthin, together with the in vivo formed meso-zeaxanthin ${ }^{(23)}$, are important in maintaining the integrity of the macula in the retina of the human eye, via photo-protection from blue light and appear to improve visual aspects in subjects with age-related macular degeneration $^{(24)}$, the most common cause of vision loss in the elderly.

In general, carotenoids can act, at least in vitro, as antioxidants (Fig. 1), acting as scavengers of singlet oxygen or reactive lipid peroxides ${ }^{(25)}$, protecting cell membranes. To which extent this function contributes to the observed health effects with human relevance is unclear, and their antioxidant properties in vivo have to some extent been questioned ${ }^{(26,27)}$. Finally, carotenoids and their metabolites, the apo-carotenoids, are likely to interact with many cellular targets such as transcription factors and nuclear hormone receptors. Important interactions could include the interruption of the NF- $\mathrm{KB}$ pathway, reducing the activation of further downstream pro-inflammatory genes, resulting in the sequestration of several cytokines (TNF $\alpha$, IL6), nitric oxide and cyclooxygenase 2 , among other ${ }^{(28)}$. Similarly, binding of carotenoids to the bound NRF2 transcription factor could result in its release and nuclear translocation, fostering the body's own antioxidant defence system, including increased expression of superoxide dismutase (SOD), catalase (CAT) and glutathione peroxidases $(\mathrm{GPX})^{(28)}$. Both increased inflammation and oxidative stress are related to several cardiometabolic complications, including type 2 diabetes $^{(29)}$ and metabolic syndrome ${ }^{(30)}$. Through their involvement as potential antioxidants and their interaction with many cellular targets, carotenoids have also been proposed to reduce the risk of several types of cancer. For instance, in a recent meta-analysis, subjects with higher carotenoid intake were shown to have lower breast cancer risk $^{(31)}$, although this may have been related to confounding factors such as increased intake of fibre. Some randomised controlled studies giving additional antioxidants such as selenium and $\alpha$-tocopherol ${ }^{(31)}$ and zinc and selenium together with $\beta$-carotene ${ }^{(32)}$ have also suggested positive effects on health, especially regarding cerebrovascular disease mortality and all-cause mortality in men, respectively.

Well known is the interplay of carotenoid metabolites with nuclear hormone receptors (summarised in Fig. 1), mainly the retinoic acid receptors (RARs) and retinoid X receptors (RXRs) and further signalling with RXR liganded heterodimers, where peroxisome proliferator-activated receptors (PPARs) appear to play an important role ${ }^{(33-36)}$ RARs and RXRs are involved in regulating the expression of a large number of genes involved in the cellular development and the immune system ${ }^{(37)}$, and PPARs are involved in the metabolism and differentiation of adipocytes ${ }^{(38)}$. Thus, carotenoids could contribute to improved immune function, including reduced risk of respiratory complications such as asthma, as reviewed previously(39) and also the reduction of perturbed lipid metabolism, a hallmark of metabolic syndrome ${ }^{(40)}$.

This review highlights the different mechanisms via which carotenoids may be related to various diseases, i.e. on the pathways involved in the respective diseases and how these are influenced by carotenoids, and emphasises common or diverging properties of these phytochemicals important for their potential health beneficial aspects.

\section{Mechanisms of action transmitted by carotenoids}

\section{Antioxidant activities}

Carotenoids as light-harvesting pigments have an important role in protecting the photosynthetic apparatus from reactive oxygen species (ROS), such as singlet oxygen, in plants and photosynthetic bacteria ${ }^{(41)}$. They can scavenge singlet oxygen in simple solutions; however, their interactions in vivo are complex; aggregated carotenoids and those spanning cell membranes can reduce their quenching efficiency. Carotenoids can also quench other free radicals to form carotene radicals with different properties ${ }^{(42)}$. These antioxidant effects include preventing oxidation of LDL particles ${ }^{(43)}$, and likely inhibiting oxidation of lipids in brain cells ${ }^{(44)}$, prevention of oxidation of polyunsaturated lipids in the retina ${ }^{(45)}$, and also by limiting oxidation of lipids during digestion in the gastro-intestinal lumen ${ }^{(46)}$. Therefore, in complex environments, the antioxidant effects of carotenoids depend on the combined properties of the radicals involved, including their concentrations.

Additionally, some carotenoids or their radicals can modulate cell signalling to induce antioxidant and detoxification enzymes, cell proliferation and apoptosis ${ }^{(46,47)}$. These complex interactions are reflected in the discrepancies between the epidemiological studies, suggesting beneficial effects of carotenoids within the normal dietary range, while it has been found difficult to prove these effects by large interventional clinical trials employing in part supra-physiological doses. Nevertheless, carotenoids are also being extensively used as food colourants ${ }^{(48)}$, dietary supplements, components of sunscreens and other cosmetic products. Their use and function will be described in the context of anti-cancer and skin-protection mechanisms.

Lycopene is among the most effective carotenoid free-radical scavengers, because the free radical compound formed with lycopene is more stable than that formed with other compounds in this group, which indicates that it can reduce, through electron transfer, also other carotenoids ${ }^{(25)}$. In vitro studies conducted by Wawrzyniak $^{(49)}$ found lycopene to be stable in acid and neutral gastric content, which was confirmed by the work of other authors $^{(50)}$ and also in the upper intestine ${ }^{(51)}$. The addition of lycopene and sodium nitrite to stomach content at the same time caused a significant decrease in the content of lycopene, and significantly lowered the concentration of sodium nitrite ${ }^{(49)}$; lycopene decrease depended on the amount of nitrite added. In in vivo studies, a decrease in blood lycopene concentrations was observed in subjects consuming higher amounts of nitrite with food products ${ }^{52)}$. In addition, oral administration of lycopene to animals showed a protective effect by lowering poisoning rates, i.e. the concentration of methemoglobin in whole blood of animals, and the concentration of nitrite and nitrate ions in the serum of rats poisoned with sodium nitrite ${ }^{(49)}$.

In an experiment carried out by Atanasowa and Pevitcharova ${ }^{(53)}$, a beneficial effect of a diet with a lycopene content of 285-640 mg (per kg of diet) was shown to reduce animal mortality after an administration of a high dose $\left(\mathrm{LD}_{50}\right)$ of sodium nitrite. This study implies that lycopene may be a compound with protective effects; although a positive contribution of e.g. vitamin $\mathrm{C}, \beta$-carotene, polyphenols and dietary fiber is also possible, as tomato paste was the source of lycopene in the diet 
of animals. Tomato paste also decreased the risk of nitrosamine formation, after administration of sodium nitrite and aminopyrine - a nitrosamine precursor ${ }^{(54)}$. In contrast to the sodium-nitrate-only exposed group, rats also receiving $236 \mathrm{mg}$ lycopene per $\mathrm{kg}$ of diet did not show circulating markers of liver damage, i.e. the activity of alanine and aspartate aminotransferase in blood were similar compared with the controls, and the livers retained their natural appearance compared with the poisoned group not receiving lycopene, where dystrophic changes occurred.

In conclusion, in healthy people, consuming cured meat (the main source of nitrite in the diet) together with vegetables and fruits is recommended, the latter as sources of carotenoids that may protect against the harmful, oxidative effects of sodium nitrite and the formation of methemoglobin. The International Agency for Research on Cancer (IARC) recognised this relationship between excessive consumption of processed meat (cured, treated at high temperatures or simmered) and the occurrence of large intestine, pancreas and prostate tumors in $2015^{(55)}$.

\section{Activation of antioxidant/anti-inflammatory cascades involving the transcription factors NF- $\mathrm{B} B$ and NRF2}

The transcription factor NF- $\mathrm{KB}$ was discovered 30 years ago ${ }^{(56)}$. It is well established that it plays a key role in adapting biological processes to environmental changes (for review, see refs. ${ }^{(57-59)}$ ). This is in particular due to a major effect on the immune system, modulating the expression of cytokines, growth factors or micro-RNAs. NF- $\mathrm{KB}$ is also involved in other gene regulation, which may have great repercussions on physiology and physiopathology processes, such as embryonic development, on the skin, the bones or the central nervous system. It also plays a key role in metabolic inflammation, proliferative and apoptotic responses, as well as in tumor formation. This great variety of effects is related to an activation mechanism associated with most stimuli.

The NF- $\mathrm{B}$ family has five members in vertebrates: RELA (better known as P65), RELB, REL, NFKB1 (P50/P105) and NFKB2 (P52/P100). In non-stimulated cells, these proteins are assembled in homo- or heterodimers and kept inactive in the cytoplasm by their association with I $\kappa \mathrm{B}$ proteins. The binding to I $\mathrm{B}$ actually prohibits translocation of NF- $\kappa \mathrm{B}$ to the nucleus. Under a great variety of stimuli, such as pro-inflammatory cytokines (TNF $\alpha$, IL1 $\beta$ ), bacterial lipopolysaccharides (LPS), phorbol esters, genotoxic agents, radiation, etc., IкB proteins are quickly

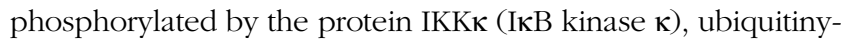
lated and finally cleaved by the proteasome. This activation pathway applies mainly to P65/P50 dimers. In addition to this conventional pathway, there is also an alternative activation pathway, in which the protein IKKк, via the phosphorylation of $\mathrm{P} 52$, leads to the release of the complex P52/RELB. The $\mathrm{NF}-\kappa \mathrm{B}$ dimers released in this way then enter the nucleus and activate the transcription of specific target genes after binding to $\mathrm{kB}$ sequence present in their promoting region. Among these target genes, we can mention anti-apoptotic genes (BCL2L1, BIRC1/2), inflammation-related genes (IL1, IL2, IL6, TNF $\alpha$ ), genes involved in cell adhesion, growth factors, chemokines, micro-RNAs, etc.
The activation of NF- $\mathrm{BB}(\mathrm{P} 65 / \mathrm{P} 50)$ depends both on the phosphorylation level of $І$ І $\mathrm{B \kappa}$ as well as the bond affinity of P65 to its response element, which may be modified by the redox state of the cell. In fact, the P65 DNA binding domain contains a high number of reactive cysteines ${ }^{(60)}$, which is why $\mathrm{NF}-\kappa \mathrm{B}$ is considered to be a redox-sensitive transcription factor. Several carotenoids or derivatives influence the NF- $\mathrm{KB}$ signalling pathway ${ }^{(61,62)}$. Therefore, they can act as anti-inflammatory compounds, in a large range of cell types where they modulate the expression of inflammation markers, via the modulation of P65 transcriptional activity. $\beta$-Carotene inhibits NF- $\kappa \mathrm{B}$ signalling in human breast cancer cells ${ }^{(63)}$, in human oesophageal squamous cell carcinoma $^{(64)}$ and in gastric epithelial AGS cells ${ }^{(65)}$. These effects are related to an inhibition of P65 translocation in conjunction with inhibition of phosphorylation and breakdown of $\mathrm{I} \kappa \mathrm{B} \kappa$.

Similar effects have been described for lycopene, on human hepatoma cells, where this compound reduces the binding capacities of P65 on its response elements ${ }^{(66)}$. This can partly explain the effect of lycopene on MMP9 expression, the reduction of which is associated with a reduction in the processes involved in the migration of cancer metastases. Similar effects of lycopene on NF- $\kappa$ B activation have also been obtained in dendritic cells ${ }^{(67)}$ and prostate and breast cancer cells ${ }^{(68)}$. Interestingly, an impact of $\beta$-carotene oxygenase 2 (BCO2) on $\mathrm{NF}-\kappa \mathrm{B}$ activity and NF- $\mathrm{-B}$ translocation and DNA binding has been reported in prostate cancer, suggesting that $\mathrm{BCO} 2$ exerts a direct effect on NF-kB signalling, independently of its enzymatic role in lycopene metabolism ${ }^{(69)}$.

The same applies to other carotenoids, such as astaxanthin, which thereby exhibits anti-inflammatory properties via inhibition of NF-kB signalling in non-small cell lung ${ }^{(70)}$, in human hepatocellular carcinoma ${ }^{(71)}$ and also shown in a hamster model of oral cancer ${ }^{(72)}$, and has been shown to display anti-inflammatory properties. Lutein acts on NF- $\kappa \mathrm{B}$ signalling to block the P65 DNA binding domain, in proliferating breast cancer cells ${ }^{(73)}$ and in gastric epithelial AGS cells ${ }^{(65)}$. Fucoxanthin reduces NF- $\mathrm{KB}$ activity in human cervical cancer cells, leading to apoptosis ${ }^{(74)}$. Similar results were depicted in breast cancer cells (MCF-7 and MDA-MB-231; ${ }^{(75)}$ ) and in human hepatoma cells ${ }^{(76)}$.

In adipocytes, a strong impact of lycopene on NF- $\kappa \mathrm{B}$ signalling was demonstrated. Indeed, lycopene and a chemically synthesised potential lycopene metabolite, apo-10'-lycopenoic acid, following incubation of 3T3-L1 adipocytes and adipose tissue explants, strongly reduced pro-inflammatory cytokines and chemokines via modulation of IKK protein phosphorylation ${ }^{(77-79)}$. Recently, similar effects of the two main lycopene isomers were observed, i.e. all-trans- and 5-cis lycopene ${ }^{(80)}$. Finally, these effects have been confirmed in vivo, in diet-induced obesity in mice supplemented with lycopene, where pro-inflammatory cytokines and chemokine expression and secretion were reduced as well as the p65 phosphorylation level ${ }^{(81)}$

NRF2 (NFE2L2) is another transcription factor that activates the antioxidant response element (ARE, also known as EpRE, electrophile response element) transcription system. ARE regulates the expression of antioxidant enzymes, such as CAT, SOD, 
GPXs and thioredoxin, and detoxifying enzymes such as heme oxygenase 1 (HO1), NAD(P)H dehydrogenase and quinone 1 (NQO1). These proteins have an important role in reducing the intracellular concentration of carcinogens and ROS and thus may reduce the progression of degenerative diseases such as cancer, osteoporosis and skin ageing, among others. Carotenoids such as lycopene, phytoene, phytofluene and astaxanthin that have been associated with a lower rate of progression of degenerative diseases were found to activate ARE in cancer cells at concentrations of $1-10 \mu \mathrm{M}^{(82)}$, in addition to several other phytochemicals, such as polyphenols, isothiocyanates and curcuminoids $^{(83)}$. In recent years, the list of carotenoids that activate ARE was extended, and this activity was found to be involved in the effect of carotenoids in various tissues and cellular systems in addition to cancer cells. For example, fucoxanthin, a marine carotenoid, increased NRF2 activation and HO1 expression in activated microglia cells ${ }^{(84)}$. Similarly, fucoxanthin reduced UVB-induced erythema through up-regulation of the HO1 protein via the NRF2 pathway ${ }^{(85)}$. The protective role of lutein against injury in rat skeletal muscle ${ }^{(86)}$ and against $\beta$-amyloid-induced oxidative stress in cerebrovascular endothelial cells ${ }^{(87)}$ was associated with an up-regulation of NRF2. Astaxanthin had a similar effect in human umbilical vein endothelial cells ${ }^{(88)}$. The role of NRF2 in mediating the protective effects of lycopene toward cancer was evident also in in vivo models. In a rat model of carcinogen-induced hepato-carcinogenesis, lycopene increased the expression of NRF2 and reversed the reduction in hepatic antioxidant enzymes (CAT, SOD, GPX) caused by the carcinogen ${ }^{(89)}$. Conversely, some studies have reported a down-regulation of the NRF2 protein $^{(63)}$ or mRNA ${ }^{(90)}$ levels by carotenoids.

Under resting conditions, NRF2 is bound to its cysteine-rich partner, Kelch-like ECH-associated protein 1 (KEAP1), which represses NRF2 activity. Various phytochemicals, such as isothiocyanates, interact with KEAP1 which leads to the release of NRF2, resulting in its translocation to the nucleus and activation of $\mathrm{ARE}^{(83,91)}$. Although dietary compounds and other chemicals that interact with KEAP1 and activate NRF2 have different molecular structures, they are all chemically reactive, and nearly all are electrophiles ${ }^{(91)}$. This allows them to react with $\mathrm{SH}$ groups of KEAP1, leading to the release of NRF2, which is now able to activate ARE. Such interaction with KEAP1 is not possible with the hydrophobic carotenoids, which generally lack any electrophilic group. Thus, it has been hypothesised that it is the carotenoid oxidation products that interact with KEAP1 and stimulate ARE. Linnewiel et al. ${ }^{(92)}$ analysed the reactivity in ARE activation of a series of chemically synthesised apo-carotenoids that can potentially be derived from in vivo metabolism of carotenoids ${ }^{(93)}$ or during their spontaneous or induced oxidation ${ }^{(94)}$. The activation of ARE by the synthetic apo-carotenals at concentrations of $10 \mu \mathrm{M}$ correlated with the number of carbon atoms between the methyl group and the terminal carbonyl group. This number of carbon atoms determines the reactivity of the conjugated double bond in reactions such as Michael addition to thiol groups of proteins. A better description of the reactivity of the double bond is the characterisation by the electron density of the molecules. Indeed, in another study ${ }^{(62)}$, the electron density values of the apo-carotenals correlated with the inhibition of NF- $\mathrm{BB}$ transcriptional activity, suggesting that inhibition of NF- $\mathrm{B}$ activity by carotenoids is also mediated by their derivatives. Other experiments in that study indicated that carotenoid derivatives could directly interact with two key proteins of the NF- $\kappa$ B pathway, probably through specific thiol groups of these proteins. It is possible that similar interactions occur between the apo-carotenals and the thiol groups of KEAP1. Although the above studies suggested that the active carotenoid derivatives are apo-carotenals, it was found that other derivatives such as apocarotenoid acids and alcohols derived from lycopene can also activate $\mathrm{ARE}^{(95)}$. However, when the reactivity of the three lycopenoids was compared via the induction of HO1 expression, it was found that the organic chemically synthesised potential human lycopenemetabolite apo-10'-lycopenal showed the strongest potential, suggesting that apo-carotenals are the most active mediators of NRF2 activation by carotenoids.

\section{Carotenoids, carotenoid metabolites and retinoids as activators of nuclear hormone receptors (Fig. 2)}

Regarding vitamin-A-like effects of carotenoids and carotenoid metabolites involving nuclear hormone receptors such as RARs and RXRs, the centric cleavage metabolites of $\beta$-carotene, the $\beta$-apo-15-carotenoids/retinoids, are further oxidised to the bioactive vitamin A derivatives, the apo-15carotenoid acids, which are named retinoic acids $33,35,96)$. These retinoic acids are well-known endogenous derivatives, functioning as lipid hormone ligands responsible for the activation of two major families of nuclear hormone receptors ${ }^{(36,97-101)}$. These nuclear hormone receptors further, after ligand activation, directly interact with the genome and modify transcription of receptor-specific genes ${ }^{(102)}$. The most abundant retinoic acid, i.e. all-trans-retinoic acid (ATRA), is the endogenous ligand of the RARs (RAR $\alpha, \beta, \gamma)^{(99,100)}$. Besides ATRA, various other geometric isomers have been identified and are endogenously present, such as 13-cis-, 9,13-dicis-, 11-cis- and 9-cis-retinoic $\operatorname{acid}^{(103-105)}$. Besides ATRA, a large focus was also placed on 9-cis retinoic acid (9CRA), which was postulated to be the endogenous ligand of the RXRs ( $\operatorname{RXR} \alpha, \beta, \gamma)^{(97,98)}$. Unfortunately, this claim is seen as highly controversial ${ }^{(106)}$, and its endogenous presence and its function as a physiologically relevant lipid hormone could not be conclusively confirmed by many groups working in the field of ultra-sensitive lipidomics (reviewed in refs. ${ }^{(106-108)}$ ). Alternatively, endogenously present geometric isomers of retinoic acid such as 13-cis-, 9,13-dicis- and 11-cis-retinoic acid were not described to be relevant for transmitting major biological activity via nuclear hormone receptor mediated signalling ${ }^{(109)}$.

Various endogenous retinoids with a non-conclusively proven endogenous relevance were identified. These ranged from the phase 1 and deactivating metabolites, the hydroxyl- or oxo-metabolites of retinoic acids ${ }^{(110)}$, and various apocarotenoids including apo- $14^{\prime}$-carotenoic acid ${ }^{(111,112)}$ apo-12'carotenoic acid ${ }^{(113)}$, apo-13'-carotenone ${ }^{(111,113-115)}$, potential apo-15-lycopenoic $\operatorname{acid}^{(34,35,116)}$ and apo-10'-lycopenoic $\operatorname{acid}^{(78,117,118)}$, originating either from BCO1/BCO2-mediated cleavage $^{(119-121)}$ or from an unspecific cleavage via radicalmediated pathways ${ }^{(94,113,122)}$. These derivatives were partly 


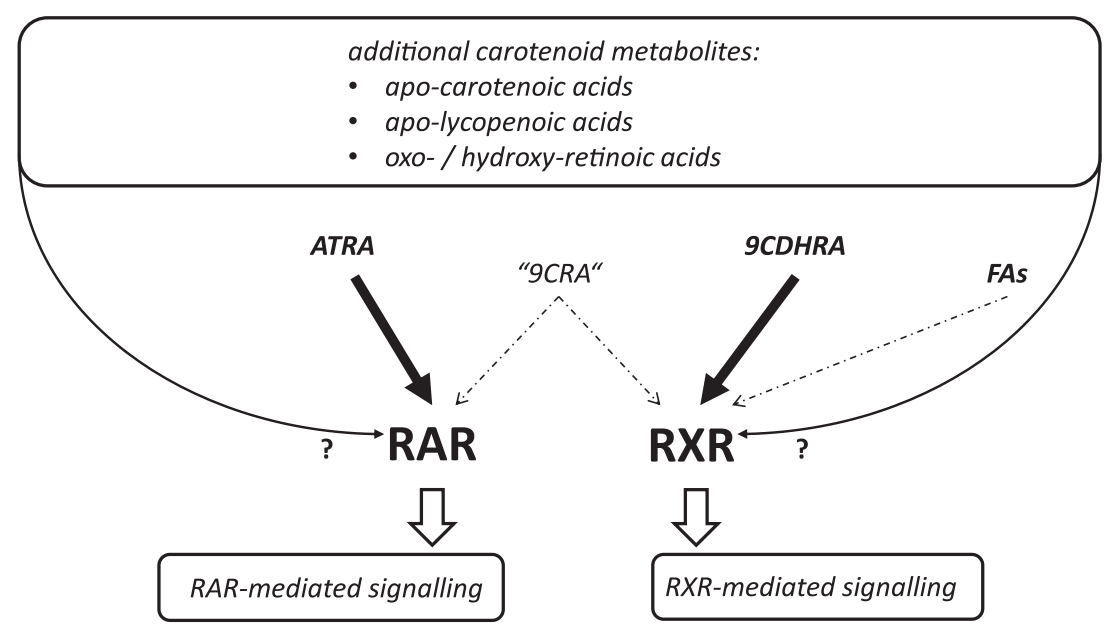

Fig. 2. Retinoids and carotenoid metabolites with known and potential nuclear hormone activation. Abbreviations: ATRA, all-trans retinoic acid; 9CRA, 9-cis-retinoic acid; 9DHCRA, 9-cis-13,14-dihydroretinoic acid; FAs, fatty acids; RAR, retinoic acid receptor; RXR, retinoid X receptor.

described as low-affinity ligands or as RAR/RXR antagonists, when the RAR or RXR is liganded by its endogenous ligand. The concept of an antagonist function of these apocarotenoids has been described in various studies ${ }^{(113,123)}$. Unfortunately, the endogenous relevance, starting from endogenous RAR activation by ATRA, which is only occurring in a short temporal and spatially restricted manner, was never clearly shown. In addition, the endogenous concentrations of these apo-carotenoids necessary at much higher levels, especially in the nucleus, where the interaction with the nuclear receptors takes place, to compete with and block ATRARAR-mediated signalling under physiological and nutritional conditions, were never reported, and their activity remains therefore speculative and was only shown under artificial conditions.

Recently, also dihydro-metabolites of apo-15-carotenoids were described to be present endogenously, ranging from 13,14-dihydroretinol ${ }^{(124-127)}$ to the additional endogenously present all-trans- and 9-cis-13,14-dihydroretinoic acids (ATDHRA/ 9CDHRA $)^{(126,128)}$, which were described as major relevant endogenous RAR as well as RXR ligands ${ }^{(126-128)}$.

The remaining question for alternative carotenoid metabolites functioning as nuclear hormone receptor ligands is the endogenous and nutritional relevance of these alternative ligands besides ATRA and 9CDHRA for RAR and RXR activation in mammalian organisms ${ }^{(107,108)}$. We can only report the perspective of presently known and potential endogenous carotenoid metabolites 'here and now' (Fig. 2), that oxo-/ hydroxyl-retinoic acids ${ }^{(129)}$, apo-carotenoic acids ${ }^{(97,99,111,113)}$ apo-carotenons $^{(113)}$ and apo-lycopenoic acids ${ }^{(35,116)}$ might be of relevance for functioning as low-affinity ligands or, less likely, as RARs ${ }^{(113)}$ and RXRs ${ }^{(113)}$ antagonists under certain still nonidentified physiological and nutritional conditions. In summary, there are many uncertainties but many options that, besides ATRA and 9CDHRA, multiple other carotenoid metabolites might be of major physiological and nutritional relevance for functioning as RAR and RXR ligands. Interferences in RAR- and RXR-mediated signalling might explain a large majority of carotenoid-mediated effects in a physiological and nutritional relevant range. Additional knowledge of these new pathways via novel carotenoid metabolites might result in more detailed insights about beneficial effects of carotenoids and in optimised suggestions for dietary intakes.

Regarding other nuclear hormone receptor mediated pathways, the RXR is the central heterodimer binding partner that interacts with the RAR or alternative nuclear hormone receptors such as the PPARs ${ }^{(130)}$ and alternative RXR-interacting heterodimer binding partners ${ }^{(131)}$. Indeed, PPAR-mediated effects were observed in white adipose tissue (WAT) of mice of $\mathrm{BCO}^{-}{ }^{-}$mice supplemented with $\beta$-carotene ${ }^{(132)}$. Recently, also carotenoid metabolites were proposed to be potential endogenous physiologically and nutritionally relevant PPAR ligands ${ }^{(34,133)}$, which was already predicted by other studies ${ }^{(134)}$. Unfortunately, the bottleneck is that these carotenoid metabolites were not conclusively identified, neither isolated nor chemically synthesised, not further tested in molecular biological assays for their biological function and, finally, not identified endogenously to claim and confirm physiological or nutritional relevance ${ }^{(34,133)}$. Therefore, this topic of carotenoid metabolites functioning as physiologically or nutritionally relevant PPAR ligands remains speculative.

Additionally, there were interactions predicted of RAR, RXR with signalling pathways mediated by sex steroid mediated signalling such as androgen receptor mediated signalling ${ }^{(135-138)}$ as well as estrogen receptor mediated signalling ${ }^{(139-143)}$. These interactions are of major importance for sex-specific diseases, including obesity/diabetes ${ }^{(144)}$ and cancer of exclusive male or female relevance, for instance, prostate cancer and breast/cervix cancers $^{(145)}$. This regulation can occur on multiple levels, involving retinoid signalling such as controlling of transcriptional expression of retinoid receptors $^{(146,147)}$, degrading metabolising enzymes ${ }^{(141)}$ and RA-synthesising enzymes ${ }^{(140)}$.

Further signalling involving alternative nuclear hormone receptors, such as the constitutive androgen receptor mediated signalling ${ }^{(148)}$ and pregnane $\mathrm{X}$ receptor mediated signalling pathways ${ }^{(149,150)}$, may also be of relevance. 


\section{Summary and evaluation of carotenoid-mediated mechanisms of action}

Antioxidant effects of carotenoids have been well described in plants as well as in a large number of in vitro and in vivo experiments with animals and human relevance. Exposure to high concentrations, typically ranging around 10 to over $100 \mu \mathrm{M}$ in in vitro experiments, as well as high nutritional dosages in human in vivo intervention trials (approximately 5-120 mg/d) have shown potential antioxidant activities, as shown by decreased markers of oxidative stress in mid-to-long-term human studies ${ }^{(33,151)}$, proposing protective effects of carotenoids on e.g. cellular membranes and lipoprotein particles. Whether these effects are based primarily on direct antioxidant effects or are transmitted also via interactions with transcription factors such as NRF2 and NF- $\mathrm{KB}$ is rather unclear.

However, concentrations at lower and more human-relevant, likely physiological carotenoid levels, i.e. below or approximately $100 \mathrm{nM} / 0.1 \mu \mathrm{M}$ in vitro, or even the lower concentrations of potential active apo-carotenoids $(\sim 1-10 \mathrm{nM})^{(152)}$ have not clearly resulted in positive antioxidant effects, and thus their physiological relevance under such conditions may be questioned ${ }^{(26)}$. It is possible that they play more prominent roles when present at high concentrations in certain parts of the body, such as during digestion, although relevant studies on this topic are missing.

Nuclear hormone receptor activation, especially by apo-15-carotenoids, which are present in the human organism at ranges of $0.1-100 \mathrm{nM}$ and are also termed retinoids, transmit their activity in the 1-10 $\mathrm{nM}$ range, and thus, human relevance seems likely ${ }^{(153)}$. An overlap between in vitro and in vivo studies and human-relevant targets was clearly described and is reviewed in ref. ${ }^{(96)}$

Promising nutri-therapeutic effects were predicted by open-chain carotenoids and mainly lycopene in male-specific cancer symptoms mainly present in the prostate ${ }^{(154)}$. While the lycopene-mediated signalling effects via RAR-mediated signalling pathways were predicted ${ }^{(34,35,155-158)}$, still no enabling lycopene metabolites were found and identified ${ }^{(159)}$, and likely novel still non-identified signalling pathways interacting with androgen receptor and estrogen receptor signalling pathways may be of further relevance.

\section{Bioavailability of carotenoids and alternative mechanisms of carotenoids}

\section{Bioavailability of carotenoids}

Carotenoids are very non-polar molecules, which are grouped in two classes, i.e., the more polar carotenoids termed xanthophylls and non-polar hydrocarbons carotenoids referred to as carotenes and requiring micellisation, i.e. incorporation into mixed micelles prior to their absorption from the small intestine. As this process requires the presence of lipids, bile salts, digestive enzymes and a certain peristalsis, this process and resulting bioavailability are limited. Typically, only approximately 5-50\% of carotenoids are absorbed and reach the circulatory system, depending on the type of carotenoid, its polarity, and food matrix, but also host-related factors ${ }^{(160,161)}$. More specifically, the more polar xanthophylls such as lutein are generally better absorbed than the apolar carotenes such as lycopene ${ }^{(162)}$. Also, the apparent chain length could play a role, with cis-carotenoids showing often a higher micellisation. Regarding the food matrix, liquid meals or heat-treated matrices resulting in macerisation of the plant cell wall generally result in higher bioavailability due to faster release kinetics ${ }^{(163)}$. In addition, meals containing certain amounts of lipids ${ }^{(164)}$, limited amounts of dietary fibre ${ }^{(165)}$ and perhaps limited amounts of minerals ${ }^{(166,167)}$ may foster carotenoid bioavailability. Among the host factors, diseases resulting in reduced absorbable surface in the intestine, possibly age, hormonal status and certain singlenucleotide polymorphisms of genes participating in cellular uptake or transport ${ }^{(168)}$ have been related to altered carotenoid bioavailability, among others.

Once absorbed, carotenoids are transported via lipoproteins to various tissues, and compartmental models have proposed various half-lives for different compartments, ranging from $2-7 \mathrm{~d}$ in plasma to $27-76 \mathrm{~d}$ in slow-exchanging tissues, likely adipocytes or muscle cells ${ }^{(168)}$. The excretion route may be via losses in bile or digestive juices, and also shorter apo-carotenoids or their resulting glucuronidated metabolites via the urine ${ }^{(168)}$ The predominant carotenoids reflect to a large extent those consumed via the diet, being namely $\beta$-carotene, lycopene, lutein, $\beta$-cryptoxanthin, $\alpha$-carotene, zeaxanthin, phytofluene and phytoene, though not necessarily in this order ${ }^{(96)}$. Thus, bioavailability is highly variable, not only between subjects but even within subjects, impeding clear cause-and-effect estimates.

\section{Disease-related mechanisms potentially modulated via carotenoid-gut microbiota interaction}

An altered gut microbiota has been correlated to a large number of diseases, including cardio-metabolic diseases and metabolic syndrome $^{(169)}$ but also cancer ${ }^{(170)}$ and neurodegenerative diseases ${ }^{(171)}$. Although very often a decreased microbial diversity is found in pathological conditions, the actual relationships between gut microbiome and diseases are still under evaluation. Recently, it was reported that, analysing available literature from 28 case-control studies, patterns of disease-related changes could be different with more or less specific shifts in the human gut microbiome ${ }^{(172)}$.

The mutual interaction between carotenoids or their derived products and the gut microbiota is still largely undefined since only a few studies have addressed this fundamental research question. It is, however, reasonable that, as a large amount of the carotenoids introduced through the diet remain unabsorbed, these compounds should reach the colon, becoming substrates for more or less extensive metabolism in this site, likely mediated by the gut microbiota ${ }^{(173)}$. It is known that a large amount of carotenoids are indeed fermented by the microbiota of the colon, into yet unknown products, following recovery fermentations ex vivo ${ }^{(174,175)}$. However, microbe-mediated carotenoid metabolism has not been thoroughly investigated. Recently, some interesting results were obtained. Most notably, in a recent intervention trial, the effect of lycopene $(7$ and $30 \mathrm{mg} / \mathrm{d}$, for 1 month) on microbiota was investigated in 30 obese subjects, by providing a diet rich in tomato products or supplements ${ }^{(176)}$. 
Lycopene showed dose-dependent increases of the relative abundance of e.g. Bifodobacterium adolescentis and B. longum. In addition, dose-dependent favourable reductions of LDL-C, LDL-peroxidase, and MDA/thiobarbituric acid reactive substances (TBARS) as markers of oxidative stress were reported. Djuric et $a l .{ }^{(177)}$ studied the association between the microbiota composition of the colon mucosa and the serum carotenoid concentrations in subjects at increased risk for colon cancer. When stratifying subjects into tertiles of serum carotenoid levels, these authors found 11 operational taxonomic units associated with higher carotenoid levels, in particular a lower abundance of Firmicutes taxa (above all, the Lachnospiraceae family). It is also relevant to note that $36 \%$ of the interindividual variance in serum carotenoid levels was explained by dietary intake, BMI, cholesterol levels, smoking and the relative abundance of Bacteroides, Roseburia and a genus of the Lachnospiraceae family. It should be mentioned that directing subjects towards a Mediterranean diet or Healthy Eating Diet for 6 months was not sufficient to change the colonic mucosal bacterial community, despite the observed increase in carotenoid intake.

Further contribution to the discussion on carotenoidmicrobiota interaction comes from the study by Karlsson et $a l^{(178)}$, who tried to understand potential associations between symptomatic atherosclerosis and gut metagenome since bacteria are considered critical factors affecting the inflammatory status of the arterial wall. An increase of genes encoding peptidoglycan synthesis and reduction of genes encoding for phytoene dehydrogenase (precursor of both lycopene and $\beta$-carotene) were found in patients with respect to controls, together with reduced levels of serum $\beta$-carotene but not lycopene. These data seem to support a potential contribution of the microbiota to the carotenoid status, even if they could not prove any direct causal relationship.

Lyu et $a l .{ }^{(179)}$, in a recent report on the effect of supplementation of $\beta$-carotene oxygenase (BCO2) knock-out (KO) mice with astaxanthin for 8 weeks, found an increased abundance of caecal Bifidobacterium spp. and higher levels of Proteobacteria and Bacteroides spp. in $\mathrm{KO}$ with respect to wild-type mice. The authors, based on this pilot study, suggested that both astaxanthin and $\mathrm{BCO} 2$ might affect gut microbiome. In this regard, the authors suggested that dietary carotenoids (e.g. $\beta$-carotene and astaxanthin) could promote gut heath through modulation of gut immune system maturation and immunoglobulin A production, likely regulating microbial dysbiosis. According to Liu et al. ${ }^{(180)}$, an improved microbiota with an increase in Akkermansia spp. was found in a mouse model of alcoholic liver disease fed with a high-fat liquid diet and supplemented with astaxanthin ( $50 \mathrm{mg} / \mathrm{kg}$ body weight) for 12 weeks. Based on this promising result, this carotenoid was suggested by the authors as a potential candidate for the treatment of bacterial disorders found in alcoholic fatty liver disease. Similarly, a modulatory effect on lipid metabolism and gut microbiota was detected in mice fed with a high-fat diet supplemented with astaxanthin $(0.005 \%$ or $0.01 \%)$ for 8 weeks $^{(181)}$.

Altogether, the data available appear too preliminary to demonstrate a direct involvement of carotenoids in the modulation of microbiota, and as far as provitamin A carotenoids are concerned, the impact on vitamin A status could be also a relevant mechanism to consider. In fact, vitamin A has been reported to play a role in the balance of the intestinal barrier ${ }^{(179)}$, and the gut microbiota was altered by a vitamin-A-deficient diet in rats and mice ${ }^{(182,183)}$. Nevertheless, a targeted analysis of microbiota-derived metabolising activities would be pivotal for the identification of the existence of a carotenoid-microbiota-host interaction.

\section{Health-beneficial effects mediated by carotenoids}

Many health-beneficial effects of carotenoids have been described, and were mainly associated with high carotenoid levels in blood as well as in organs ${ }^{(38,184)}$. The connection to a reduced intake of fruits and vegetables, which are high in carotenoids, was rapidly drawn. However, fruits and vegetables are also rich in a large variety of additional health-beneficial organic compounds, including polyphenols, antioxidant vitamins $\mathrm{C}$ and $\mathrm{E}$, and dietary fibre, among others ${ }^{(185)}$. A clear distinction of health-beneficial effects dedicated to one single carotenoid or even one single carotenoid metabolite with one mechanistic target has been aimed for, but has thus far not been clearly shown. It seems more likely that multiple carotenoids, with multiple carotenoid metabolites, acting via multiple mechanistic pathways in concert are responsible for the observed actions. Here, we try to describe, based on obesity and skin/lung cancer, the current situation and multiple mechanisms identified in experimental studies. A targeted supplementation with carotenoids, aiming at better health, is preferred for specific diseases such as of the macula, while, alternatively, a healthy diet rich in fruits and vegetables is likewise recommended but unfortunately not well accepted by a convenience-lifestyledriven general population.

\section{Carotenoids and obesity}

In recent years, a novel perspective on the function and health benefits of carotenoids and carotenoid-derived products is emerging that connects these compounds to lipid and energy metabolism in homeostatic tissues, decreased body fat accumulation and the control of adipocyte biology, with possible implications for the aetiology and management of obesity and obesity-related metabolic disorders such as insulin resistance, diabetes and cardiovascular disease ${ }^{(186-192)}$.

Adipose tissue, in addition to the liver, is an important site of carotenoid and retinol storage/accumulation ${ }^{(193-195)}$. It has been estimated that $15-20 \%$ of total body retinol in rats is stored in adipose tissue, in particular in the adipocytes ${ }^{(195)}$. Carotenoids are found in adipocytes mainly in the lipid droplets, and also in association with cell membranes ${ }^{(196)}$. Carotenoid concentrations in abdominal fat depots show a strong association with both dietary carotenoid intake and plasma carotenoid concentrations in humans ${ }^{(197-199)}$. Provitamin A carotenoids and retinol in adipocytes may serve to regulate systemic vitamin A homeostasis since adipose tissue produces retinol-binding protein and adipose retinol/retinyl esters stores are readily mobilised under conditions of dietary vitamin A deficiency ${ }^{(200)}$. Additionally, different lines of evidence support specific activities of 
carotenoids and retinoids in adipose tissue and adipocyte biology (see below).

Adipose tissue expresses all intracellular binding proteins, enzymes and transcription factors involved in carotenoid and retinoid metabolism and function, including the carotenoid cleavage enzymes BCO1 and BCO2 ${ }^{(189-201)}$. Retinal and ATRA have been detected in adipose tissue, in the case of ATRA at relatively high levels compared with other tissues ${ }^{(202-204)}$. Studies suggest a crosstalk of intracellular retinoid metabolism and lipid droplet dynamics, with a physical association of enzymes of retinoid metabolism with the lipid droplet coat that appears to depend on active acyl ester biosynthesis ${ }^{(205,206)}$. Animal ${ }^{(207)}$ and human ${ }^{(208-211)}$ studies have revealed a differential expression of genes for carotenoid/retinoid-metabolising enzymes in visceral and subcutaneous adipose tissues, which display important differences regarding developmental origin, metabolism, endocrinology, capacity for adipogenesis and the health risk they entail ${ }^{(212,213)}$. Genetic ablation of different carotenoid/ retinoid-metabolising enzymes and transport proteins results in alterations of adiposity and defects in brown adipose tissue (BAT) thermogenesis in mice ${ }^{(200,214,215)}$ Furthermore, adipocyte functions such as the thermogenic capacity of BAT in rodents are dependent on the animal's vitamin A status ${ }^{(212,214,216)}$

Accumulating evidence links carotenoids and carotenoid metabolites to the inhibition of adipocyte differentiation (adipogenesis) and the reduction of fat storage in mature adipocytes, through suppression of PPAR $\gamma$, a master regulator of adipogenesis and the mature adipocyte phenotype. Carotenoids and carotenoid derivatives function in this sense either by acting possibly as PPAR $\gamma$ antagonist ligands - e.g. retinal ${ }^{(217)}$, apo-14' -carotenal $^{(218)}$ and intact astaxanthin ${ }^{(219)}$ - or by repressing PPAR $\gamma$ expression secondarily to RAR activation e.g. ATRA ${ }^{(220)}$, intact $\beta$-carotene ${ }^{(221)}$ and $\beta$-cryptoxanthin ${ }^{(222)}$. Among other mechanisms, interference with $\mathrm{C} / \mathrm{EBP}$ action on the PPAR $\gamma$ promoter by liganded RAR is an important contributor to ATRA-dependent inhibition of adipogenesis ${ }^{(223)}$. How retinoid-activated RAR inhibits PPAR $\gamma$ in the mature adipocyte is not known, but mechanisms similar to those involved in the inhibition of adipogenesis may be involved.

Importantly, carotenoids and carotenoid-derived products with anti-adiposity action, besides antagonising or repressing PPAR $\gamma$, are able to promote lipid oxidation in adipose and other tissues. Dietary supplementation with carotenoids such as $\beta$-carotene, fucoxanthin, astaxanthin, crocetin and $\beta$-cryptoxanthin - among others - or treatment with retinoids such as ATRA and retinal enhance systemic fat catabolism and energy expenditure in rodents, resulting in an anti-obesity action which is not due to reduced food intake ${ }^{(187,188,192)}$. Focusing on adipose tissues, early studies showed that ATRA, as well as $\beta$-carotene and other provitamin A carotenoids, increases uncoupling protein 1 (UCP1) and, thus, the capacity for energy expenditure through enhanced BAT thermogenic function ${ }^{(186)}$. More recently, fucoxanthin $^{(224)}, \quad \beta$-cryptoxanthin ${ }^{(225)}$, lycopene ${ }^{(226)}, \operatorname{ATRA}^{(227,228)}$ and retinal $^{(209)}$ have been shown to stimulate WAT oxidative capacity and features of WAT browning, which may also contribute to greater energy expenditure. Effects in adipose tissues most likely result from the combination of direct action of the carotenoids/ retinoids in these tissues and their systemic effects. For instance,
ATRA treatment in mice induces UCP1 at the transcriptional level in adipocytes and mobilises the browning-inducing myokine irisin from skeletal muscle ${ }^{(229)}$.

Mechanisms of gene expression regulation are better known for ATRA. Several genes for proteins in energy and lipid catabolism are up-regulated at the transcriptional level, following ATRA binding to the canonical RAR moiety (or the PPAR $\beta / \delta$ moiety) of RXR heterodimers and subsequent recruitment of cofactor complexes on the target gene promoter ${ }^{(187)}$. In addition, some RXR heterodimers (so-called permissive) respond to ligands of either partner and are synergistically activated when both ligands are bound, providing a mechanism for widespread effects of retinoids on gene expression ${ }^{(230)}$. Notably, liver X receptor (LXR) and PPAR isoforms, which are deeply involved in the control of different aspects of lipid metabolism, act on (at least some) target genes as permissive heterodimers with $\operatorname{RXR}^{(231,232)}$. Finally, retinoids may impact cell metabolism through extragenomic actions, such as retinoylation (acylation by retinoic acid) of proteins and, especially, the activation of protein kinase cascades such as p38 mitogen-activated protein kinase (P38 MAPK or MAPK14) or AMP-activated protein kinase $(\mathrm{AMPK})^{(38,187,188)}$.

Closely related to its metabolic role, adipose tissue has an important endocrine function: it produces and secretes many signalling molecules including proteins (collectively named adipokines), as well as immunomodulatory factors whose altered production in obesity links visceral obesity to associated metabolic disturbances ${ }^{(233)}$. By altering the endocrine function of adipose tissues, carotenoids and their conversion products may elicit adipose-driven effects in distant organs protective against obesity and/or its clinical complications. Carotenoids and their conversion products affect the secretory profile of adipose tissue by affecting the activity of target transcription factors and inflammatory pathways, and possibly also in part in a passive manner, i.e. secondary to effects on adipocyte lipid content and body fat. Studies have shown that $\beta$-carotene and ATRA can actively suppress adipose production of leptin, resistin and retinal-binding protein 4 (RBP4) - three adipokines for which elevated serum levels associate with inflammation and insulin resistance in humans and rodents ${ }^{(234)}$ - whereas capsanthin/capsorubin, crocetin, fucoxanthin, lycopene and $\beta$-carotene (but not ATRA) can up-regulate adiponectin - an adipokine that is down-regulated in obesity and with well-established insulinsensitising, anti-inflammatory and anti-atherogenic action ${ }^{(235)}$ (reviewed in refs. ${ }^{(38,187,188,192)}$ ).

Anti-inflammatory action of carotenoids in adipose tissue may relate to carotenoids' ability to reduce oxidative stress, considering that excess ROS production in obese adipose tissue is a pro-inflammatory, pathogenic mechanism of obesity-associated metabolic syndrome ${ }^{(236)}$. Antioxidant properties of carotenoids stem from their scavenging function toward reactive species and, especially, their ability to activate the NRF2 pathway and, hence, cellular antioxidant defences, and to suppress the NF- $\mathrm{B}$ pathway, thus inhibiting downstream production of inflammatory cytokines ${ }^{(28,38,187,188)}$. At the adipocyte level, antioxidant action has been evidenced for $\beta$-carotene, astaxanthin, fucoxanthin and crocetin and anti-inflammatory action for lycopene and fucoxanthin, and its potential metabolites 
apo-10'-lycopenoic acid and fucoxanthinol, as well as ATRA ${ }^{(237)}$. Nevertheless, under certain conditions, carotenoids may be pro-oxidants in cells, when highly reactive oxidative breakdown products accumulate ${ }^{(238)}$ or when carotenoid detoxifying mechanisms are compromised ${ }^{(239)}$.

In humans, epidemiological studies have consistently reported decreased serum levels of carotenoids, including $\beta$-carotene in overweight and obese individuals, both adults and children/adolescents, and an inverse association between circulating carotenoid concentrations and measures of obesity, such as BMI or waist circumference, and of obesity-related metabolic disorders ${ }^{(240)}$ (reviewed in ref. ${ }^{(188)}$ ). The inverse association of serum total and individual carotenoids levels with metabolic syndrome is confirmed in a recent meta-analysis ${ }^{(241)}$. The concentration of carotenoids in adipose tissue ${ }^{(188)}$ and isolated adipocytes ${ }^{(242)}$ is also lower in obese people. In addition, obese individuals showed a reduced efficiency of $\beta$-carotene conversion to retinoids ${ }^{(243)}$. In a recent prospective study, circulating ATRA levels at baseline predicted the development of metabolic syndrome at 4-year follow-up ${ }^{(244)}$. However, an association of vitamin A status as serum retinol levels with human obesity or metabolic syndrome is less clear ${ }^{(188,240,241)}$. Studies have also pointed to an association between higher dietary intakes of carotenoids (as evaluated through food frequency questionnaires) and reduced adiposity and development of obesity-related metabolic diseases ${ }^{(245,246)}$. Despite the epidemiological evidence, intervention trials to assess carotenoids in relation to adiposity in humans are scarce. Nevertheless, beneficial effects on adiposity in overweight and obese humans have been achieved through supplementation of carotenoid mixtures (either pure or in the form of plant juices or extracts), at doses lower than those that caused concern and controversy in the past in large-scale $\beta$-carotene intervention trials $^{(188,247,248)}$. Evidence from intervention studies of antiobesity action is mainly related to $\beta$-carotene, $\beta$-cryptoxanthin, fucoxanthin and paprika xanthophylls.

Taken together, many cell culture and animal studies indicate that specific carotenoids and carotenoid derivatives impact in direct and indirect manners essential aspects of adipose tissue biology, including the control of adipogenesis, adipocyte metabolism (relative capacities for fat storage and oxidation), the production of regulatory signals and inflammatory mediators, and oxidative stress. These aspects may be of special relevance in regard to obesity, as obesity entails inflammation of adipose tissue ${ }^{(233)}$ and the development of hypertrophic adipocytes in which oxidative stress is exacerbated ${ }^{(236)}$. More human intervention and mechanistic studies are needed to verify the potential of specific carotenoids against obesity and 'sick fat' and to fully understand the connection of carotenoids with the control of adiposity.

\section{Carotenoids and cancer}

The potential of carotenoids to prevent the onset of certain cancers has been studied for many years ${ }^{(249-251)}$, but conclusive mechanisms of action are still not clearly known. Besides the antioxidant effects mainly found in experimental models that have never been conclusively confirmed in humans, the antioxidant/anti-inflammatory cascades involving the transcription factors NF-кB (RELA) and NRF2 (NLF2L2, section B2) and nuclear hormone receptor activation potential by mainly carotenoid metabolites (section B3) have been implicated. In addition, effects on cell cycle control, differentiation and apoptosis in RAR-, RXR- and partly PPAR-mediated pathways may be modified by retinoids as carotenoid metabolites ${ }^{(252-254)}$. As cancer is a heterogeneous disease, in this review we focus on two types of cancer: skin and lung cancer.

Skin cancer and carotenoids. Skin cancers are one of the most common forms of human neoplasia and can be divided into two groups: melanoma cancer, with one of the highest rates of morbidity and mortality among all cancers ${ }^{(255)}$ and nonmelanoma cancers (NMSC), including basal cell carcinoma (BCC) and squamous cell carcinoma (SCC), which are rarely lethal ${ }^{(256)}$. In the development of skin cancer and skin aging, UV radiation is considered the most important environmental factor, indicating the need for some chemoprotective agents to slow down the increasing incidence ${ }^{(257)}$.

One important mechanism for skin cancer prevention is the photo-protective effects of carotenoids. Carotenoids, especially $\beta$-carotene, lycopene, astaxanthin, canthaxanthin and lutein were investigated as photo-protective agents in several human intervention studies, mainly as agents which prevent solar erythema formation ${ }^{(258)}$ and photo-induced carcinogenesis, but also for photo-aging prevention ${ }^{(259)}$. Both, antioxidant mechanism as well as blue-light filtering properties of carotenoids ${ }^{(260)}$, could play a role. Their role as provitamin A compounds, protective pigments, efficient antioxidants and anti-inflammatory agents makes them attractive candidates for skin protection. Consequently, carotenoids have been used as both oral supplements and as a component of topical sunscreen products.

UV radiation is associated with approximately $65 \%$ of melanoma cases and $90 \%$ of non-melanoma skin cancers ${ }^{(257)}$ Despite the primary prevention measures, using sunscreen and wearing protective clothing are highly promoted ${ }^{(261,262)}$. DNA damage induced by UVB (290-320 nm) radiation primarily leads to the formation of dimeric lesions, with the main dimeric photolesions being cyclobutane pyrimidine dimers and pyrimidine (6-4) photoproducts $(6-4 \mathrm{PPs})^{(259,263,264)}$, DNA strand breaks, and DNA cross-links ${ }^{(257)}$. Moreover, excessive exposure to UV induces mutations of P53 and loss of FAS-FASL interaction. Keratinocytes with these mutations become resistant to apoptotic pathways, and consequently, the expansion of these clones eventually leads to the formation of squamous cell carcinomas and/or actinic keratoses ${ }^{(265)}$. On the other hand, UVA $(320-400 \mathrm{~nm})$ radiation leads to oxidative damage in the cell with formation of ROS, oxidative stress and oxidation of nucleotide bases, the main lesion being 8-oxo-7,8-dihydroguanine ${ }^{(255)}$. ROS affect several signalling pathways such as c-Jun N-terminal kinase (JNK or MAPK8), myelocytomatosis oncogene (MYC), Keap1, mitogen-activated protein kinases (MAPKs), NRF2, MAPK14, P53, protein kinase C, RAS, RAF, and even more ${ }^{(266)}$.

Sunscreen products are designed to protect the skin from the harmful effects of UV wavelengths of sunlight, namely UVB (280-315 nm) and UVA (315-400 nm), that reach the Earth's surface $^{(267)}$. UVB can damage the DNA directly, while UVA acts 
mainly through ROS intermediates ${ }^{(268)}$. Chromophores in the skin, including melanin, porphyrins, heme, cytochromes and riboflavin, can absorb UVA photons. Singlet oxygen and other ROS are formed if this absorbed energy is subsequently transferred to oxygen. Environmental pollutants, including polycyclic aromatic hydrocarbons, can act synergistically with UVA to increase the production of superoxide and singlet oxygen. Overexposure to UV radiation contributes to the development of skin cancers and skin ageing ${ }^{(268)}$. Therefore, many cosmetic products (sunscreen lotions, creams, shampoo, hair dyes and varnishes, lipsticks, etc.) contain different UV filters to either reflect or absorb UV light ${ }^{(269,270)}$. Sunscreens on the market tend to protect better against UVB than UVA radiation. Haywood and co-workers have reported that sunscreens with broad-spectrum UV protection reduce free radical formation by $55 \%(271)$. Carotenoids may act as accessory pigments and provide photo-protection by dissipation of excess light energy by quenching the excited triplet state molecules and singlet oxygen, Therefore, their addition complementing the protection of UV filters may represent an added value to sunscreens ${ }^{(272)}$. Another strategy may be the activation antioxidative mechanisms ${ }^{(273)}$. This is hinted at by the observation that moderate physical activity, inducing mild oxidative stress, may increase skin tolerance to harmful levels of oxidative stress ${ }^{(274)}$.

Sunscreens are one of the most widely applied strategies by the public to protect themselves from UV irradiation; nevertheless, topical treatments with antioxidants, especially carotenoids, are less tested than oral supplementation ${ }^{(275)}$. The combination of oral and topical lutein and zeaxanthin treatments provided better antioxidant protection than either treatment alone; the least effective was the topical treatment alone, as it was inferior even to oral carotenoid administration ${ }^{(276)}$. $\beta$-Carotene is a major constituent of commercially available oral sun protectants, but studies proving protective effect of oral and topical treatment with $\beta$-carotene against skin responses to sun exposure are scarce and conflicting ${ }^{(277)}$. Short-term oral supplementation of carotenoids resulted in a range of outcomes, from protection against photo-damage, to no protection observed, to possible pro-oxidative properties at higher dosages and synergistic effects between the antioxidants. Published successful studies are described in Table 1 . The efficacy of $\beta$-carotene for systemic photo-protection seems to depend on the dose and duration of the treatment; it seems that at least 10 weeks of carotenoid treatment are needed for a measurable short-term improvement for systemic photo-protection against erythema formation ${ }^{(278)}$. Additionally, synergistic effects between different antioxidants are important to increase the protection against ROS. $\beta$-Carotene as well as other carotenoids, such as lutein and lycopene, can ameliorate UV-induced erythema in humans ${ }^{(279)}$. The combination of carotenoids and other antioxidants is also effective, as was shown for the synergistic effects of other groups of antioxidants. For example, ascorbate can regenerate $\alpha$-tocopherol from its phenoxyl radical in many model systems ${ }^{(280)}$, selenium and niacin are required to keep glutathione in its active form ${ }^{(274,281)}$ and the vitamin C radical may be recycled by GSH non-enzymatically ${ }^{(282)}$. The beneficial effects of combined antioxidants were reported by Cesarini et $a l^{(283)}$, based on a study on 25 healthy individuals receiving an antioxidant complex and vitamins (lycopene, $\beta$-carotene, $\alpha$-tocopherol and selenium) that improved epidermal defence and reduced UV-induced damage. Gollnick et al. ${ }^{(284)}$ concluded that supplementation with moderate dosages of $\beta$-carotene $(30 \mathrm{mg} / \mathrm{d}$ ) before and during sunlight exposure can protect against sunburns, possibly because of increased absorption capacity of the skin or because $\beta$-carotene concentration in the skin does not decrease to below the concentration considered to be critical. On the other hand, post-supplementation with $\beta$-carotene may have detrimental effects, most probably due to its effect on accelerated cell proliferation ${ }^{(285)}$.

While carotenoids have been shown to inhibit the UV-induced epidermal damage and tumor formation in mouse models ${ }^{(286)}$, these data were not reproduced in large long-term human intervention studies so far ${ }^{(274)}$. Therefore, oral supplementation of antioxidants, including carotenoids, without a specific medical diagnosis, is not recommended at the moment.

Interest in the use of natural products as a possible treatment option of skin cancer is growing, as $70 \%$ of anti-cancer drugs are obtained from natural sources ${ }^{(286)}$. Carotenoids are promising anti-cancer agents and able to interfere with the cell cycle ${ }^{(251)}$. Effects of carotenoid administration may differ, depending on the stage of malignant transformation. In normal cells, they may reduce the frequency of the malignant transformation by ROS-induced damage prevention or by induction of cellular repair and adaptive stress responses. Increased ROS formation can protect from cancer by increasing the oxidative stress/ damage and eliminating the damaged cells ${ }^{(287)}$. The reduction of ROS by antioxidants can lead to the survival of preinitiated tumor cells even in unnatural matrix environments ${ }^{(288)}$. Likewise, the increased administration of antioxidants and possibly carotenoids during cancer promotion, progression and treatment phases may increase the cancer cell survival rate by enhanced resistance against oxidative stress and decreased $\operatorname{apoptosis}^{(289)}$. Carotenoids may act as accessory pigments and provide photo-protection by dissipation of excess light energy and by quenching excited triplet state molecules and singlet oxygen $^{(272)}$.

A likely more important mechanisms compared with simple low-efficient photo-protective effects of carotenoids, again, is the function of carotenoids to function as RAR-ligand precursors ${ }^{(290)}$. ATRA, the active metabolite of provitamin A carotenoids, can interfere with RAR signalling, which is protective against cancer, especially skin cancer, with induction of apoptosis of cells which may be pre-cancerous ${ }^{(291)}$. Skin and plasma carotenoid concentrations decrease with UV irradiation in human volunteers ${ }^{(292)}$. UV exposure has also been associated with local vitamin A deficiency which could be preventable by ATRA pre-treatment ${ }^{(293)}$ and likely by local and topical provitamin A pre-treatment - not to forget, the beneficial effect of ATRA and alternative other RAR activators, in skin cancer therapy ${ }^{(294,295)}$.

Lung cancer and carotenoids. $\beta$-Carotene is an effective antioxidant in vitro, and it has been hypothesised that it is also effective in vivo ${ }^{(296)}$. Indeed, epidemiological studies have suggested that high dietary $\beta$-carotene reduces the risk for several types of cancer, including lung cancer ${ }^{(297,298)}$. Smokers and asbestos-exposed subjects have an increased lung cancer 
Table 1. Effects of carotenoid supplementation for skin protection

\begin{tabular}{|c|c|c|c|c|c|}
\hline Compound administered & Dose given & Duration & Population & Results & Ref. \\
\hline O: $\beta$-carotene & 30 and $90 \mathrm{mg} / \mathrm{d}$ & $90 \mathrm{~d}$ & 30 healthy females & $\begin{array}{l}\text { prevention of photoaging }(30 \mathrm{mg} / \mathrm{d}) \\
\text { pro-oxidant activity }(90 \mathrm{mg} / \mathrm{d}) \text { in the skin }\end{array}$ & (390) \\
\hline $\begin{array}{l}\text { O: vitamin E plus } \beta \text {-carotene } \\
\text { supplementation }\end{array}$ & $\begin{array}{l}\alpha \text {-tocopherol }(400 \mathrm{IU} / \mathrm{d}) \\
\quad \beta \text {-carotene }(15 \mathrm{mg} / \mathrm{d})\end{array}$ & 8 weeks & 16 healthy subjects & $\begin{array}{l}\text { vitamin } E \text { or } \beta \text {-carotene supplementation had no effect on } \\
\text { skin sensitivity to UV radiation }\end{array}$ & (391) \\
\hline $\begin{array}{l}\text { O: total carotenoids and } \\
\text { combination with } \\
\alpha \text {-tocopherol }\end{array}$ & $\begin{array}{l}25 \mathrm{mg} \text { total carotenoids/d and a } \\
\text { combination of the carotenoid } \\
\text { supplement and vitamin } \\
\text { E [335 mg (500 IU) } \\
\text { RRR- } \alpha \text {-tocopherol/d] }\end{array}$ & 12 weeks & $\begin{array}{l}20 \text { healthy subjects } \\
(6 \text { men and } \\
14 \text { women) }\end{array}$ & $\begin{array}{l}\text { diminished erythema on dorsal skin (back) after week } 8 \\
\text { erythema suppression was greater with the combination of } \\
\text { carotenoids and vitamin } E \text { than with carotenoids alone }\end{array}$ & (392) \\
\hline $\begin{array}{l}\text { O: } \beta \text {-carotene and carotenoid } \\
\text { mixture }\end{array}$ & $\begin{array}{l}\beta \text {-carotene }(24 \mathrm{mg} / \mathrm{d}) \text { and } 24 \mathrm{mg} / \mathrm{d} \\
\text { of a carotenoid mixture } \\
(\beta \text {-carotene, lutein and lycopene } \\
(8 \mathrm{mg} / \mathrm{d} \text { each) }\end{array}$ & 12 weeks & $\begin{array}{l}12 \text { volunteers for each } \\
\text { study group }\end{array}$ & $\begin{array}{l}\text { erythema intensity } 24 \mathrm{~h} \text { after irradiation was significantly lower } \\
\text { in both groups receiving carotenoid supplements for } 12 \\
\text { weeks compared with non-supplemented controls }\end{array}$ & (279) \\
\hline $\begin{array}{l}\text { O: antioxidant and vitamin } \\
\text { complex }(A O C) \text { : lycopene, } \\
\beta \text {-carotene, } \alpha \text {-tocopherol, } \\
\text { selenium }\end{array}$ & $\begin{array}{l}\text { twice a day: } 3 \mathrm{mg} \text { of natural } \\
\alpha \text { - and } \beta \text {-carotenes, } 3 \mathrm{mg} \text { of } \\
\text { tomato lycopene, } 5 \mathrm{mg} \text { of natural } \\
\alpha \text {-tocopherol, and } 37.5 \mathrm{\mu g} \text { of } \\
\text { organic selenium }\end{array}$ & 7 weeks & 25 healthy individuals & improved epidermal defence against UV-induced damage & (283) \\
\hline O: $\beta$-carotene & $30 \mathrm{mg} / \mathrm{d}$ & $\begin{array}{l}10 \text { weeks pre-supple-mentation; } \\
13 \text { d exposure }\end{array}$ & $\begin{array}{l}20 \text { young female } \\
\text { students }\end{array}$ & erythema development was lower in the supplemented group & (284) \\
\hline $\begin{array}{l}\text { OT: lutein and zeaxanthin } \\
\text { Topical } 5 \% \text { lutein in } \\
\text { butylene glycol }\end{array}$ & $\begin{array}{l}\text { twice a day: lutein } 50 \text { ppm, } \\
\text { zeaxanthin } 3 \text { ppm. Oral, topical } \\
\text { or combined administration }\end{array}$ & 12 weeks & 40 healthy women & $\begin{array}{l}\text { the highest degree of protection after UV skin irradiation from } \\
\text { the combined administration; better protection from oral lutein } \\
\text { administration than topical }\end{array}$ & (276) \\
\hline $\mathrm{T}: \beta$-carotene & $2 \mathrm{mg} / \mathrm{cm}^{2}$ of $0.2 \% \beta$-carotene & $\begin{array}{l}30 \text { min between cream } \\
\text { application and first } \\
\text { measurement }\end{array}$ & $\begin{array}{l}12 \text { healthy volunteers } \\
\text { (skin type II) }\end{array}$ & protection of human skin when exposed to IR radiation & (393) \\
\hline
\end{tabular}

Type of administration: O, oral; OT, oral and topical; T, topical. 
risk $^{(299)}$, in combination with a lower $\beta$-carotene status ${ }^{(300)}$. The hypothesis that $\beta$-carotene has the ability to decrease lung cancer risk was tested in the Alpha-Tocopherol $\beta$-Carotene (ATBC) randomised control trial ${ }^{(301)}$. In this study, smokers were supplemented with $20 \mathrm{mg} \beta$-carotene per day and/or vitamin E $(50 \mathrm{mg} / \mathrm{d})$. The study was performed in 29,133 male participants with a median duration of 6.1 years, resulting in an average $\beta$-carotene concentration of $5.59 \mu \mathrm{M} \beta$-carotene in blood after 3 years of intervention ${ }^{(302)}$. In the same period, this hypothesis was also tested in the Carotene and Retinol Efficacy (CARET) trial $^{(303)}$, which used doses of $\beta$-carotene and vitamin A several times above the normal, average level ${ }^{(151)}$. Indeed, smokers and asbestos-exposed subjects were supplemented with $30 \mathrm{mg} \beta$-carotene and 25,000 IU retinyl palmitate per day. This CARET study was performed with 18,314 participants (males and post-menopausal females) with a median duration of 3.7 years, resulting in an unknown increase in $\beta$-carotene plasma concentration. The CARET and the ATBC studies surprisingly resulted in an increased, rather than a decreased, lung cancer risk $^{(301,303)}$. The ATBC study also reported other detrimental effects, such as an increased risk for cardiovascular diseases ${ }^{(304)}$, and the CARET study reported an increased mortality due to coronary heart disease $\mathrm{e}^{(13)}$. The outcome contrasts with that of a study with 22,071 non-smoking male physicians, where the subjects were supplemented with $50 \mathrm{mg} \beta$-carotene every alternating day, resulting in $2.24 \mu \mathrm{M} \beta$-carotene in the blood. In this study, $\beta$-carotene supplementation did not result in any observed detrimental effects ${ }^{(305)}$. The fact that the volunteers in this study were non-smoking, in contrast to the ATBC study and the CARET study, has been used as an explanation for the different outcome, but, for example, also the supplement intake regimen differed: every other day in this study, versus every day in the ATBC and CARET studies.

The ATBC and CARET studies have shed doubt on the use of $\beta$-carotene as a supplement and have resulted in cautionary advice of the EFSA to not consume more than $25 \mathrm{mg} \beta$-carotene per day, especially in combination with smoking ${ }^{(306)}$. To be able to fully and safely exploit the beneficial effects that are associated with high dietary carotenoid intake, it is necessary to understand the mechanisms behind the observed adverse effects in the ATBC and CARET trials. Mechanistic studies are, however, hampered by the availability of animal models that reflect human $\beta$-carotene metabolism. In humans, a large percentage of $\beta$-carotene, $30-70 \%$, depending on genotype ${ }^{(307)}$, is taken up intact. This is not the case in rodents, which are animal models well suited for mechanistic studies. Compared with humans, rodents have a more active variant of $\mathrm{BCO}^{(308)}$, the enzyme that centrally cleaves $\beta$-carotene. This happens already in the intestinal epithelial cells upon uptake, and hardly any $\beta$-carotene can be found in circulation. Since ferrets do have a $\beta$-carotene metabolism that resembles that of humans, ferrets have been used as an animal model for mechanistic studies into functional effects of $\beta$-carotene. However, due to a lack of molecular tools at the time, only few possible mechanisms of $\beta$-carotene action were identified. Most notably, physiological $(0.43 \mathrm{mg} / \mathrm{kg}$ body weight $/ \mathrm{d}) \quad \beta$-carotene concentrations resulted in an increase in ATRA concentrations in the lung in smoke-exposed ferrets, while pharmacological concentrations
(2.4 mg/kg body weight/d) decreased ATRA concentrations and RAR $\beta^{(309)}$. Part of this effect has been explained by smoke-induced $\beta$-carotene oxidation. Vitamins $\mathrm{E}$ and $\mathrm{C}$ have been shown to decrease oxidative breakdown of $\beta$-carotene. Indeed, $\beta$-carotene supplementation in combination with these vitamins resulted in higher ATRA concentrations than after $\beta$-carotene supplementation alone ${ }^{(310)}$. However, other mechanisms may have played a role. In inflammation, which is associated with smoking, plasma $\beta$-carotene concentrations decreased to a higher extent than the plasma concentrations of the more oxidation-sensitive carotenoids lycopene and lutein ${ }^{(310,311)}$. Indeed, examination of deposited human microarray gene expression data showed that smoking results in increased expression of alcohol dehydrogenase 7 (ADH7) $)^{(312-315)}$. ADH7 is the most important enzyme in the conversion of retinol to retinal $^{(316)}$, indicating that smoking not only imposes oxidative stress, but also affects vitamin A homeostasis. Moreover, higher protein levels of phosphorylated JNK, MAPK14 (P38) and Jun proto oncogene (JUN), were observed in groups exposed to smoke with higher, non-nutritionally relevant dose of $\beta$-carotene compared with smoke-exposed ferrets alone. On the other hand, physiological doses of $\beta$-carotene to smoke-exposed ferrets decreased phosphorylated levels of JNK, MAPK14 and $\mathrm{JUN}^{(317)}$. JNK and MAPK14, members of the MAPK family, mediate cellular responses to cytokines and environmental stress and may play an important role in inflammation and carcinogenesis $^{(318)}$. In another study performed in ferrets, $\beta$-carotene was used in combination with benzo[a]pyrene, the major carcinogenic compound from cigarette smoke. $\beta$-Carotene reduced $\mathrm{C}$-centred radicals in vitro and in vivo, while $\mathrm{OH}$-centred radicals were increased in vitro, but remained unaffected in vivo, likely due to up-regulation of DNA damage repair ${ }^{(27)}$. No evidence for adverse effects was found in this study.

Mechanisms of $\beta$-carotene supplementation for cancer protection. Detailed mechanistic studies became possible owing to the availability of a mouse model in which BCO1 was inactivated $\left(\mathrm{BCO}^{-/-}\right)^{(201)}$. Like humans, $\mathrm{BCO}^{-/-}$mice displayed increased plasma $\beta$-carotene upon $\beta$-carotene supplementation and accumulated $\beta$-carotene in the lung upon $\beta$-carotene supplementation ${ }^{(201)}$. To identify molecular effects of $\beta$-carotene, female and male $\mathrm{BCO} 1^{-/-}$mice were supplemented with either 1500 IE vitamin A per $\mathrm{kg}$ diet, to assure vitamin A sufficiency, or with 1500 IE vitamin A plus $150 \mathrm{mg} \beta$-carotene per $\mathrm{kg}$ of diet, and whole genome microarray analysis was performed. Of interest, differences were observed in the response to $\beta$-carotene supplementation between male and female mice. In fact, only a limited number of genes were commonly regulated between female and male mice ${ }^{(319)}$. In total, 1522 genes were regulated by $\beta$-carotene in the lung of $\mathrm{BCO}^{-/-}$females and 1474 in males ${ }^{(319)}$. Out of these, only 89 genes were affected in both sexes, of which the large majority, 85 , were regulated in the opposite direction ${ }^{(319)}$. The functional responses also differed. BCO1 inactivation appeared to increase the requirement for vitamin $\mathrm{A}$ in females, which was alleviated by $\beta$-carotene supplementation, despite the absence of $\mathrm{BCO}^{(320)}$. This effect on inflammation was not observed in male 
$\mathrm{BCO}^{-/-}$mice ${ }^{(321)}$. Rather, in the lung of $\mathrm{BCO}^{-/-}$mice males, two genes were strongly down-regulated by $\beta$-carotene: frizzled class receptor 6 (FZD6) and collagen triple helix repeat containing 1 (CTHRC1) ${ }^{(319)}$, both genes having a role in developmental WNT signalling ${ }^{(91,322-324)}$. Differences between males and females were also observed in the post-intervention period of the CARET study (the ATBC study concerned males only), with larger relative risks of lung cancer mortality (1.33 versus 1.14; $P=0.36)$, cardiovascular disease mortality ( 1.44 versus 0.93 ; $P=0.03)$, and all-cause mortality ( 1.37 versus $0.98 ; P=0.001)$ in the post-menopausal females ${ }^{(325)}$.

Do the mechanistic data explain the adverse effects? To clarify downstream effects of FZD6 down-regulation and assess human relevance, Fzd6 was inactivated, using RNAi, in BEAS2B cells, human type 2 bronchial epithelial cells, and whole-genome gene expression was analysed ${ }^{(326)}$. The genes that were regulated both in vitro by FZD6 inactivation in BEAS2B cells and in vivo by $\mathrm{BC}$ in the lungs of the male $\mathrm{BCO} 1^{-/-}$mice had 'cell cycle, proliferation, oncogenes' as their signature ${ }^{(326)}$. Further inspection of the FZD6 and $\beta$-carotene controlled genes revealed a strong enrichment of genes controlled by the transcription factors JUN (the target of JNK) and activating transcription factor 2 (ATF2, a major target of MAPK14) ${ }^{(326)}$. Of note, also retinoid receptors are transcription targets of $\mathrm{JUN}^{(252)}$. Identified JUN/ATF2 target genes included forkhead box M1 (FOXM1) as well as centromere protein (CENPE), kinesin family member 11 (KIF11) and cell division cycle associated 8 (CDCA8). FOXM1 is a transcription factor with a regulatory role in mitosis (CENPE, KIF11) and cell division (CDCA8). Strikingly, in BAES2B human lung cells, in smoke- and $\beta$-carotene-exposed ferret lungs and in $\beta$-carotene-exposed lungs of $\mathrm{BCO}^{-1-}$ mice, the JUN and MAPK14 signalling pathways are affected ${ }^{(318,321,326)}$, strongly suggesting that high dosages of $\beta$-carotene can affect these developmental pathways. Does this explain carcinogenicity of $\beta$-carotene? Although it is tempting to say yes, this is not necessarily the case, since development is a normal physiological process. For example, it is well established that retinoid signalling has an important role in developmental processes, including development of the lung ${ }^{(327)}$. Only dysregulation of developmental processes, for example, by sustained activation of JUN, can lead to aberrant cell behaviour and proliferation. Furthermore, it is not straightforward to interpret the functional consequences of JUN and MAPK14 activation, since functional effects are context dependent ${ }^{(318)}$ and depend on interaction of JUN and MAPK14 ${ }^{(328)}$. Recently, it was observed in vitro in colon cancer cells that exposure to $\beta$-carotene altered miRNA expression, associated with up-regulation of histone acetylation and DNA methylation ${ }^{(329)}$. Together with the observation in a mouse model that inactivation of BCO1, which may potentially also have affected the exposure to dietary vitamin A, affected miRNA expression associated with WNT signalling ${ }^{(330)}$, this hints to a role for $\beta$-carotene/vitamin A metabolism in regulating miRNAs, also affecting developmental regulatory pathways.

A possible role of the supplementation regimen exists as well. The subjects in the ATBC and CARET study were supplemented daily with a high dose of $\beta$-carotene for a long period (median of 6.1 years with $20 \mathrm{mg} / \mathrm{d}$ of $\beta$-carotene and 3.7 years with $30 \mathrm{mg} / \mathrm{d}$ of $\beta$-carotene, respectively). Such a continuous supplementation regimen differs substantially from dietary intake, which is rather variable. Continuous supplementation poses a constant pressure on associated pathways. This can possibly result in a lower threshold for dysregulation, paving the way for the increased lung cancer risk in smokers and in asbestos-exposed subjects, as was observed in the ATBC and CARET studies ${ }^{(13,301)}$. It is interesting to note that in a study that involved a less continuous exposure, with every-other-day intake of supplements, no adverse effects were observed ${ }^{(305)}$. As mentioned before, this study involved non-smokers, rather than smokers, former smokers or asbestos workers as in the ATBC and CARET studies. That variable intake compared with continuous intake has a strong effect on health outcomes is exemplified by a study in APOE3L mice ${ }^{(331)}$. These mice are prone to developing cardiovascular disease when given a high-fat high-cholesterol diet. In this particular study, the mice were given (i) a high-fat control diet; (ii) the control diet with high cholesterol (1\%), alternating the control diet $(4 \mathrm{~d})$ and the control diet with high cholesterol (3 d); or (iii) the control diet with an intermediate level of cholesterol $(0.43 \%)$ corresponding to the average cholesterol intake of the alternating diet. Remarkably, the alternating diet, but not the intermediate diet, showed the strongest reduction in inflammation and atherosclerosis, with inflammation being at the level of the control diet and atherosclerosis being $50 \%$ reduced, although still being higher than the control ${ }^{(331)}$. Similarly, the beneficial effects of intermittent fasting on metabolic health ${ }^{(332)}$ and aging ${ }^{(333)}$ are clear, without inducing the strong changes in body weight and body composition that are associated with caloric restriction $^{(334)}$. Dampening of signalling and induction of compensatory responses may play a role, as is suggested by the disappearance of effectiveness of anti-diabetic treatment over time (335) $^{(3)}$

Insights into possible consequences of prolonged exposure to high dosages of retinoids can be obtained from studies in which acute promeyelocytic leukaemia patients are treated with ATRA as a therapeutic agent. Without any other medication, approximately $25 \%$ of the patients develop retinoic acid syndrome. Typical for the clinical manifestations of retinoic acid syndrome are pulmonary effects and that a large percentage of patients suffer from inflammatory infiltrates ${ }^{(336,337)}$. Although the exact mechanisms are unknown, these data indicate that an increase in retinoic acid might become detrimental under certain conditions. ATRA levels are thought to be very well regulated $^{(338)}$. Since the measurement of ATRA involves sophisticated equipment, the ATRA precursor retinol is measured in most studies that investigated effects of carotenoids. In contrast to the assumed stable ATRA levels, consumption of $\beta$-carotene-rich carrot juice for 2 weeks resulted in stable retinol plasma concentrations but almost doubled ATRA plasma concentrations $^{(290)}$. Also in the studies with $\mathrm{BCO}^{-/-}$mice, a positive correlation between $\beta$-carotene concentrations in lung and retinyl ester concentrations in the lung was observed ${ }^{(320,321)}$. This indicates that there is a controlled balance between concentrations of $\beta$-carotene and its stored form. What happens with ATRA levels after prolonged supplementation with $\beta$-carotene is unknown, but, for example, prolonged ATRA treatment causes an increase in retinoid catabolism and can lead to retinoic acid resistance ${ }^{(339,340)}$. This is mainly caused by an increased 
cytochrome P 450 family 26 (CYP26) capacity. These studies indicate that retinoid levels may be altered after $\beta$-carotene administration and that prolonged periods of elevated retinoid levels can induce an increase in retinoid catabolism. This hypothesis is more or less strengthened by some adverse effects that have been observed in ATRA therapy. Administration of ATRA can induce retinoid hyper-catabolism, and patients cannot be actively treated with ATRA after a first therapy even when the dose is doubled ${ }^{(341,342)}$. Moreover, decreases in endogenous retinol stores down to $40 \%$ have been observed in patients with exogenous retinoid therapy and resulted in adverse effects on vision $^{(343)}$. Moreover, retinoic acid syndrome is characterised by weight gain (ATRA increase results in the opposite ${ }^{(336)}$ ) in association with pulmonary infiltrations. Together this suggests that prolonged exposure with $\beta$-carotene may induce changes in retinoid metabolism, possibly inducing retinoid resistance. This enforces the suggestion that the continuity of the supplementation may be a factor that could have contributed to the outcomes of the ATBC and CARET studies, although it is unclear whether this is due to retinoid resistance or prolonged activation of frizzled signalling or both.

Genotypes and susceptibility to develop lung cancer following $\beta$-carotene supplementation. Although it is acknowledged that high doses of $\beta$-carotene can increase the risk to develop lung cancer in smokers or subjects who have been exposed to asbestos, it is important to note that only a low percentage of the subjects who took $\beta$-carotene supplements in the ATBC and CARET studies developed lung cancer. More precisely, 72 subjects out of 7283 of the ATBC study and 49 subjects out of 9420 subjects of the CARET study developed lung cancer, which was apparently due to the $\beta$-carotene supplement. This shows that only a very small fraction of the population, i.e. about $0.5-1 \%$ of the subjects who smoked and/or had been exposed to asbestos were sensitive to the $\beta$-carotene supplement. The most likely explanation of this observation is that these subjects bore genotypes that led to the adverse effect of $\beta$-carotene. Indeed, most of the phenotypic differences between individuals, as well as their susceptibility to develop different diseases, are due to genetic variations ${ }^{(344,345)}$. We hypothesise that different genotype(s) can be responsible for the adverse effect of $\beta$-carotene on lung cancer. These genotypes can be located in the genes that are implicated in either the bioavailability or the metabolism of $\beta$-carotene or in the interaction between $\beta$-carotene or, most likely, its metabolites and the genes involved, directly or indirectly, in lung cancer. Indeed, we believe that genotypes that modulate the bioavailability and the metabolism of $\beta$-carotene can modify both the concentration of the parent molecule and its metabolites in the sites where they modulate the mechanisms involved in the development of lung cancer. Although all these genetic variations are far from known, some of them have been identified and have been listed in recent reviews ${ }^{(307,346-348)}$. The second set of genes where some genetic variations might explain the sensitivity of some subjects to develop lung cancer following $\beta$-carotene supplementation is the four genes that have been suggested to be involved in the adverse effect of $\beta$-carotene on lung cancer, i.e. ADH7, JNK, MAPK14 and JUN. Of course, these genes exhibit genetic polymorphisms (https://www. ncbi.nlm.nih.gov/snp), and several studies have shown association between genetic variants at these genes and cancer. It is not the topic of this review to comprehensively list all these associations; thus, only some illustrating references are provided. For example, a genetic variant in ADH7 (rs1573496) has been associated with aerodigestive cancer ${ }^{(349)}$. Furthermore, carriers of MAP2K7 rs3679T genetic variant had an increased risk of lung cancer $^{(350)}$. Finally, some genetic variants of C-Jun increase the risk of lung cancer via interaction with smoking or drinking ${ }^{(351)}$.

In summary, it is highly likely that the adverse effects of $\beta$-carotene that were observed in about $1 \%$ of the subjects who were enrolled in the ATBC and CARET studies were due to peculiar genotypes in the genes involved in either the bioavailability and the metabolism of $\beta$-carotene and/or in lung cancer related genes that are targets for $\beta$-carotene metabolites. Future studies additionally genotyping their volunteers will perhaps confirm this hypothesis and identify genotypes, or more likely combinations of genotypes, which result in an increased risk to develop a lung cancer when taking additional $\beta$-carotene supplements.

\section{Health-beneficial effects of carotenoids and carotenoid degradation products. More matters?}

Due to the limited knowledge in the area of carotenoid metabolites, functioning as ligands of nuclear hormone ligands and further signalling, it should be discussed whether more ligands and more nuclear hormone mediated signalling is purely seen as beneficial or might also be seen as detrimental for human health. RAR-mediated signalling is responsible for a large variety of physiologically mediated pathways, ranging from central physiological pathways such as the induction of differentiation $^{(352,353)}$, apoptosis ${ }^{(354,355)}$, cell cycle control ${ }^{(356-358)}$, lipid homeostasis $^{(187,359,360)}$ and proliferation ${ }^{(352,361)}$, which are of high importance for processes of embryonic development ${ }^{(362,363)}$, reproduction $^{(364,365)}$, epidermal homeostasis and regeneration $^{(366,367)}$, immune responses ${ }^{(368,369)}$ and maintenance of bone, brain, nervous and cardiovascular functions ${ }^{(370-372)}$. Too low or too high levels of endogenous ATRA ${ }^{(373)}$, due to a dysfunctional or stressed retinoid homeostasis, while hard to define what the upper and lower threshold levels are, were seen to be risk factors for various previously mentioned physiological functions and are associated with further disease development, where retinoid signalling is dysfunctional. It is commonly accepted that too low retinoid levels are associated with cancer, obesity, reduced immune responses and disorders of the nervous system. Provitamin A carotenoids, as major retinoid precursors, can therefore be seen as dietary derivatives with a unique beneficial function, especially for these listed dysfunctions related to retinoid signalling. Alternatively, too high levels of retinoidmediated signalling were also associated with various diseases in these specific areas, including diabetes ${ }^{(368,374,375,376)}$, increased immune responses/allergies ${ }^{(377-381)}$ and osteoporosis ${ }^{(382)}$.

Besides functioning as a precursor for the RARs, carotenoids were also reported to be precursors of RXR ligands ${ }^{(107,383)}$. RXR-mediated signalling includes the controversially discussed 
RXR-RXR-mediated signalling while mainly functioning as a heterodimer binding partner for permissive and non-permissive heterodimers ${ }^{(384,385)}$. Permissive signalling is mainly mediated via RXR-PPAR- and RXR-LXR-mediated signalling ${ }^{(131)}$. Especially lipid metabolism and homeostasis are major axes under control of these pathways ${ }^{(384,386)}$ and seen as highly beneficial for the prevention of cardiovascular diseases ${ }^{(387,388)}$. We predict that certain carotenoids might be preferred nutritional precursors of RXR ligands ${ }^{(106)}$ and therefore might be highly beneficial for the prevention of cardiovascular diseases.

Besides the regular recommendation of 'more matters', referring to dietary intake of carotenoids, preferably distinct single and multiple carotenoid dietary suggestions should be focused on. This is especially relevant for carotenoids such as lutein and zeaxanthin, which are, in contrast to $\beta$-carotene, lycopene and $\beta$-cryptoxanthin, not predominantly consumed via natural food, from food with added ingredients or even targeted dietary supplements. Their intakes are determined exclusively by fruit and vegetable intake, which is low to intermediate in large groups of Western society. More targeted specific recommendations for selected groups of fruits and vegetables or, alternatively, nutritional extracts high in specific carotenoids or even dietary supplements may further boost a specific carotenoid intake and adaptations for specific populations, such as for certain age and gender groups, lifestyles, ethnicities, athletes, etc., may be envisioned.

In addition, as summarised, we observe a large variety in endogenous levels of carotenoids in humans, which not only depends on individual dietary intake but is mainly due to our human genetic diversity (reviewed in ref. ${ }^{(168)}$ ). Here, a focus should be put on further examination of carotenoid metabolite levels, nuclear hormone mediated ligand signalling monitoring with transcriptomic or other omics techniques to ensure a healthy life. Further approaches, for instance, personal nutrition based on individual needs, should be also highlighted for nutrition-related carotenoid research.

\section{Conclusions and dietary suggestions}

Carotenoids may act in humans as antioxidants and photoprotective compounds, while likely a larger activity range is mediated via the transcription factors NF- $\mathrm{KB}$ and NRF2 as well as the nuclear hormone receptors RARs and RXRs. It is likely that the list of transcription factors or nuclear receptors activated by carotenoids and more specifically by a larger variety of identified and even not yet identified carotenoid metabolites is far from being conclusively identified.

With relevance for larger population groups, specific epigenetic mechanisms are co-involved in carotenoid-mediated signalling. This new field of research will require intensive investigations regarding the influence starting from carotenoid intake, towards carotenoid and further carotenoid-metabolite levels and transmitted biological signalling.

In addition, as carotenoids are well-known markers of fruit and vegetable intake, their blood levels in humans may simply function as indicators of food intake, lifestyle and health markers.
Based on this review, the following dietary suggestions can be drawn:

A. A high intake of fruits and vegetables that are rich in a variety of carotenoids, and many other beneficial compounds, is advised. An upper limit for fruit and vegetable intake is not needed, because it seems unlikely that even the highest intake of fruit and vegetables is likely to pose any adverse risk from the carotenoid point of view.

B. Single carotenoids as supplements, except for lutein and zeaxanthin for eye health, did until now not conclusively show any health beneficial effects. Possibly, a more complex dietary supplementation and combination may be needed to yield clear health-beneficial effects, which may depend on each individual's personal needs. High-dose supplement intake of $\beta$ carotene is warned against by the EFSA for individuals at risk for lung cancer, i.e. (previous) smokers ${ }^{(389)}$.

C. Simple recommendations using terms such as 'more matters' and 'antioxidants are good' may do more harm than good and are detrimental for a clear evaluation of beneficial health effects of carotenoids and impairs advice for a healthy balanced diet and/or targeted carotenoid supplementation.

\section{Acknowledgements}

The concept of the publication and its final layout was created thanks to the involvement of J.D-L, R.R and T.B. Contribution in the preparation of chapters and tables, in writing publications: M.L.B.; P.B.; J.C-R.; Y.v H.; J.K.; J-F.L.; M.R.L.; B.O.A.; B.P.; J.R.; M. P.; P.R.; J.R.; B-W.R.; Y.S.; P.T.; R.T.; A.W.; R.R.; J.D-L. All authors read and agreed on the final version.

\section{Financial support}

This article is based on work from the European Cooperation in Science and Technology (COST) Action CA15136, European Network to Advance Carotenoid Research and Applications in Agro-Food and Health (www.eurocaroten.eu), supported by COST.

\section{Conflicts of interest}

The authors declare no conflicts of interest.

\section{Individual author contribution}

The entire manuscript, summary of sections and conclusions/ dietary suggestions were set up and directed by the three equal contributors Dr. Joanna Dulińska-Litewka, Dr. Torsten Bohn and Dr. Ralph Rühl.

The introduction was written by Torsten Bohn. Each chapter was mainly compiled by individual groups of co-authors: Subchapter 'Antioxidant activities' by Dr. Irina Milisav. Sub-chapter 'Activation of antioxidant/anti-inflammatory cascades involving 
the transcription factors NF- $\kappa$ B and NRF2' by Drs. Yoav Sharoni and Jean-Francois Landrier. Part about Carotenoid metabolites and retinoids as activators of nuclear hormone receptors' by Ralph Rühl and Joanna Dulińska-Litewka. Sub-chapter 'Bioavailability of carotenoids and alternative mechanisms of carotenoids' by Torsten Bohn. Sub-chapter 'Disease-related mechanisms potentially modulated via carotenoid-gut microbiota interaction' by Marisa Porrini, Patrizia Riso and Torsten Bohn. Sub-chapter 'Carotenoids and obesity' by Drs. Joan Ribot, M. Luisa Bonet and Jean-Francois Landrier, Sub-chapter 'Carotenoids and cancer' by Drs. Patrick Borel, Ralph Rühl, Jaap Keijer, Joanna Dulińska-Litewka, Yvonne van Helden. Chapter 'Health-beneficial effects of carotenoids and carotenoid degradation products. More matters?' by Ralph Rühl.

\section{References}

1. Umeno D, Tobias AV \& Arnold FH (2002) Evolution of the C30 carotenoid synthase CrtM for function in a C40 pathway. J Bacteriol 184, 6690-6699.

2. Giuffrida D, Sutthiwong N, Dugo P et al. (2016) Characterisation of the $\mathrm{C} 50$ carotenoids produced by strains of the cheese-ripening bacterium Arthrobacter arilaitensis. Int Dairy J 55, 10-16.

3. Yabuzaki J (2017) Carotenoids database: structures, chemical fingerprints and distribution among organisms. Database 2017, bax004.

4. Hashimoto H, Uragami C \& Cogdell RJ (2016) Carotenoids and photosynthesis. Subcell Biochem 79, 111-139.

5. Buijsse B, Feskens EJ, Schlettwein-Gsell D et al. (2005) Plasma carotene and $\alpha$-tocopherol in relation to 10-y all-cause and cause-specific mortality in European elderly: The Survey in Europe on Nutrition and the Elderly, a Concerted Action (SENECA). Am J Clin Nutr 82, 879-886.

6. Aune D, Keum N, Giovannucci E et al. (2018) Dietary intake and blood concentrations of antioxidants and the risk of cardiovascular disease, total cancer, and all-cause mortality: a systematic review and dose-response meta-analysis of prospective studies. Am J Clin Nutr 108, 1069-1091.

7. Donaldson MS (2011) A carotenoid health index based on plasma carotenoids and health outcomes. Nutrients $\mathbf{3}$ 1003-1022.

8. Böhm V, Lietz G, Olmedilla-Alonso B et al. (2020) From carotenoid intake to carotenoid blood and tissue concentrations implications for dietary intake recommendations. Nutr Rev doi: 10.1093/nutrit/nuaa008.

9. Nebeling LC, Forman MR, Graubard BI et al. (1997) The impact of lifestyle characteristics on carotenoid intake in the United States: the 1987 National Health Interview Survey. Am J Public Health 87, 268-271.

10. Segovia-Siapco G, Burkholder-Cooley N, Haddad Tabrizi S et al. (2019) Beyond meat: a comparison of the dietary intakes of vegetarian and non-vegetarian adolescents. Front Nutr 6, 86

11. Calder PC, Ahluwalia N, Brouns F et al. (2011) Dietary factors and low-grade inflammation in relation to overweight and obesity. BrJ Nutr 106, S5-S78.

12. Kritchevsky SB, Bush AJ, Pahor M et al. (2000) Serum carotenoids and markers of inflammation in nonsmokers. Am J Epidemiol 152, 1065-1071.

13. Omenn G, Goodman G, Thornquist M et al. (1996) Effects of a combination of beta carotene and vitamin A on lung cancer and cardiovascular disease. N Engl J Med 334, 1150-1155.
14. Blumberg J (1994) The alpha-tocopherol, beta-carotene cancer prevention study in Finland. Nutr Rev 52, 242-245.

15. Burrows TL, Williams R, Rollo M et al. (2015) Plasma carotenoid levels as biomarkers of dietary carotenoid consumption: a systematic review of the validation studies. J Nutr Intermed Metab 2, 15-64.

16. Grune T, Lietz G, Palou A et al. (2010) $\beta$-carotene is an important vitamin A source for humans. J Nutr 140, 2268S-2285S.

17. Foster A (1988) Vitamin A deficiency and its control. Br J Ophthalmol 72, 476-476.

18. West KP (2015) Epidemiology and prevention of Vitamin A deficiency disorders. in The Retinoids: Biology, Biochemistry, and Disease 505-527 (Wiley Blackwell). doi:10.1002/978111 8628003.ch23.

19. Vijayaraghavan K (2018) National control programme against nutritional blindness due to vitamin a deficiency: current status \& future strategy. Indian J Med Res 148, 496-502.

20. Chiu M, Dillon A \& Watson S (2016) Vitamin A deficiency and xerophthalmia in children of a developed country. J Paediatr Child Health 52, 699-703.

21. Timoneda J, Rodriguez-Fernandez L, Zaragoza R et al. (2018) Vitamin A deficiency and the lung. Nutrients 10, 1132.

22. Wirth JP, Petry N, Tanumihardjo S et al. (2017) Vitamin a supplementation programs and country-level evidence of vitamin A deficiency. Nutrients 9, 190.

23. Nolan JM, Meagher K, Kashani S \& Beatty S (2013) What is meso-zeaxanthin, and where does it come from? Eye (Basingstoke) 27, 899-905.

24. Arunkumar R, Calvo CM, Conrady CD et al. (2018) What do we know about the macular pigment in AMD: the past, the present, and the future. Eye (Basingstoke) 32, 992-1004.

25. Krinsky NI \& Johnson EJ (2005) Carotenoid actions and their relation to health and disease. Mol Aspects Med 26, 459-516.

26. Erdman JW, Ford NA \& Lindshield BL (2009) Are the health attributes of lycopene related to its antioxidant function? Arch Biochem Biophys 483, 229-235.

27. van Helden Y, Keijer J, Heil S et al. (2009) Beta-Carotene affects oxidative stress-related DNA damage in lung epithelial cells and in ferret lung. Carcinogenesis 30, 2070-2076.

28. Kaulmann A \& Bohn T (2014) Carotenoids, inflammation, and oxidative stress-implications of cellular signaling pathways and relation to chronic disease prevention. Nutr Res 34, 907-929.

29. Zheng H, Guo J, Jia J et al. (2019) The effect of probiotic and synbiotic supplementation on biomarkers of inflammation and oxidative stress in diabetic patients: a systematic review and meta-analysis of randomized controlled trials. Pharmacol Res 142, 303-313.

30. Grandl G \& Wolfrum C (2018) Hemostasis, endothelial stress, inflammation, and the metabolic syndrome. Semin Immunopathol 40, 215-224.

31. Hu F, Wang Yi B, Zhang W et al. (2012) Carotenoids and breast cancer risk: a meta-analysis and meta-regression. Breast Cancer Res Treat 131, 239-253.

32. Hercberg S, Galan P, Preziosi P et al. (2004) The SU.VI.MAX study: a randomized, placebo-controlled trial of the health effects of antioxidant vitamins and minerals. Arch Intern Med 164, 2335-2342.

33. Bohn T, Desmarchelier C, Sedef N et al. (2019) Symposium 2: Nutrient interactions and their role in protection from chronic diseases: $\beta$-Carotene in the human body: Metabolic bioactivation pathways - From digestion to tissue distribution and excretion. in Proc Nutr Soc vol. 78 68-87 (Cambridge University Press). 
34. Caris-Veyrat C, Garcia A, Reynaud E et al. (2016) A review about lycopene-induced nuclear hormone receptor signalling in inflammation and lipid metabolism via still unknown endogenous apo-10'-lycopenoids. Int J Vitam Nutr Res 86 , $62-70$.

35. Aydemir G, Kasiri Y, Birta E et al. (2013) Lycopene-derived bioactive retinoic acid receptors/retinoid-X receptors-activating metabolites may be relevant for lycopene's anti-cancer potential. Mol Nutr Food Res 57, 739-747.

36. Dulińska-Litewka J, Sharoni Y, Hałubiec P et al. (2021) Recent progress in discovering the role of carotenoids and their metabolites in prostatic physiology and pathology with a focus on prostate cancer - a review - part i: molecular mechanisms of carotenoid action. Antioxidants 10, 585.

37. Savory JGA, Edey C, Hess B et al. (2014) Identification of novel retinoic acid target genes. Dev Biol 395, 199-208.

38. Bonet ML, Canas JA, Ribot J et al. (2016) Carotenoids in adipose tissue biology and obesity. Subcell Biochem 79, 377-414.

39. Melo van Lent D, Leermakers E, Darweesh S et al. (2016) The effects of lutein on respiratory health across the life course: a systematic review. Clin Nutr ESPEN 13, e1-e7.

40. Iqbal J, Al Qarni A, Hawwari A et al. (2017) Metabolic syndrome, dyslipidemia and regulation of lipoprotein metabolism. Curr Diabetes Rev 14, 427-433.

41. Frank HA \& Brudvig GW (2004) Redox functions of carotenoids in photosynthesis. Biochemistry $\mathbf{4 3}, 8607-8615$.

42. Böhm F, Edge R \& Truscott G (2012) Interactions of dietary carotenoids with activated (singlet) oxygen and free radicals: potential effects for human health. Mol Nutr Food Res $\mathbf{5 6}$ 205-216.

43. Kiokias S, Proestos C \& Oreopoulou V (2018) Effect of natural food antioxidants against LDL and DNA oxidative changes. Antioxidants 7, 133.

44. Craft NE, Haitema TB, Garnett KM et al. (2004) Carotenoid, tocopherol, and retinol concentrations in elderly human brain. J Nutr Heal Aging 8, 156-162.

45. Saccà SC, Cutolo CA, Ferrari D et al. (2018) The eye, oxidative damage and polyunsaturated fatty acids. Nutrients 10, 668.

46. Kanner J \& Lapidot T (2001) The stomach as a bioreactor: dietary lipid peroxidation in the gastric fluid and the effects of plant-derived antioxidants. Free Radic Biol Med 31, 1388-1395.

47. Palozza P, Catalano A, Simone R et al. (2012) Lycopene as a guardian of redox signalling. Acta Biochim Pol 59, 21-25.

48. De Mejia EG, Zhang Q, Penta K et al. (2020) The colors of health: chemistry, bioactivity, and market demand for colorful foods and natural food sources of colorants. Ann Rev Food Sci Technol 11, 145-182.

49. Wawrzyniak A, Szkola Glowna Gospodarstwa Wiejskiego, Warszawa (Poland), Katedra Zywienia Czlowieka (2006) Interaction of sodium nitrite and lycopene in the in vitro and in vivo conditions. (Wydawnictwo SGGW).

50. Bilton R, Gerber M, Grolier P et al. (2001) The White Book on Antioxidants in Tomatoes and Tomato Products and Their Health Benefits; Final report of the Concerted Action FAIR the CT97-3233.

51. Kopec R, Caris-Veyrat C, Nowicki M et al. (2019) The effect of an iron supplement on lycopene metabolism and absorption during digestion in healthy humans. Mol Nutr Food Res 63 , e1900644.

52. Kalaycloğlu $Z$ \& Erim FB (2019) Nitrate and nitrites in foods: worldwide regional distribution in view of their risks and benefits. J Agric Food Chem 67, 7205-7222.

53. Atanassova V \& Pevitcharova G (1997) Study of the influence of food products on nitrite serum content and rat mortality (fr. Étude de l'influence de certains produits alimentaires sur la teneur sérique en nitrites et la mortalité de rats. Med Nutr 5, 199-203.

54. Atanasova-Goranova VK, Dimova PI \& Pevicharova GT (1997) Effect of food products on endogenous generation of $n$-nitrosamines in rats. Br J Nutr 78, 335-345.

55. Goodson WH, Lowe L, Carpenter D et al. (2015) Assessing the carcinogenic potential of low-dose exposures to chemical mixtures in the environment: the challenge ahead. Carcinogenesis 36, S254-S296.

56. Sen R \& Baltimore D (1986) Multiple nuclear factors interact with the immunoglobulin enhancer sequences. Cell $\mathbf{4 6}$, 705-716.

57. Hayden MS \& Ghosh S (2004) Signaling to NF-кB. Genes Dev 18, 2195-2224.

58. Elsharkawy AM \& Mann DA (2007) Nuclear factor- $\kappa B$ and the hepatic inflammation-fibrosis-cancer axis. Hepatology $\mathbf{4 6}$, 590-597.

59. Zhang Q, Lenardo MJ \& Baltimore D (2017) 30 Years of NF-кB: a blossoming of relevance to human pathobiology. Cell $\mathbf{1 6 8}$, $37-57$.

60. Liu H, Colavitti R, Rovira II et al. (2005) Redox-dependent transcriptional regulation. Circ Res 97, 967-974.

61. Sharoni Y, Linnewiel-Hermoni K, Khanin M et al. (2012) Carotenoids and apocarotenoids in cellular signaling related to cancer: a review. Mol Nutr Food Res 56, 259-269.

62. Linnewiel-Hermoni K, Motro Y, Miller Y et al. (2014) Carotenoid derivatives inhibit nuclear factor kappa B activity in bone and cancer cells by targeting key thiol groups. Free Radic Biol Med 75, 105-120.

63. Sowmya Shree G, Yogendra Prasad K, Arpitha H et al. (2017) $\beta$-carotene at physiologically attainable concentration induces apoptosis and down-regulates cell survival and antioxidant markers in human breast cancer (MCF-7) cells. Mol Cell Biochem 436, 1-12.

64. Zhu X, Zhang Y, Li Q et al. (2016) $\beta$-carotene induces apoptosis in human esophageal squamous cell carcinoma cell lines via the Cav-1/AKT/NF- $\mathrm{BB}$ signaling pathway. J Biochem Mol Toxicol 30, 148-157.

65. Kim Y, Seo JH \& Kim H (2011) $\beta$-Carotene and lutein inhibit hydrogen peroxide-induced activation of NF- $\mathrm{BB}$ and IL-8 expression in gastric epithelial AGS cells. J Nutr Sci Vitaminol (Tokyo) 57, 216-223.

66. Huang CS, Fan YE, Lin CY et al. (2007) Lycopene inhibits matrix metalloproteinase-9 expression and down-regulates the binding activity of nuclear factor-kappa B and stimulatory protein-1. J Nutr Biochem 18, 449-456.

67. Kim G, Kim J, Ahn S et al. (2004) Lycopene suppresses the lipopolysaccharide-induced phenotypic and functional maturation of murine dendritic cells through inhibition of mitogenactivated protein kinases and nuclear factor- $\mathrm{\kappa B}$. Immunology 113, 203-211.

68. Assar EA, Vidalle MC, Chopra M et al. (2016) Lycopene acts

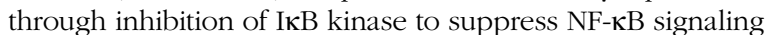
in human prostate and breast cancer cells. Tumor Biol 37, 9375-9385.

69. Gong X, Marisiddaiah R, Zaripheh S et al. (2016) Mitochondrial $\beta$-carotene $9^{\prime}, 10^{\prime}$ oxygenase modulates prostate cancer growth via NF- $\mathrm{KB}$ inhibition: a lycopeneindependent function. Mol Cancer Res 14, 966-975.

70. Cheng J \& Eroglu A (2020) The promising effects of astaxanthin on lung diseases. Adv Nutr doi: 10.1093/advances/ nmaa143.

71. Li J, Dai W, Xia Y et al. (2015) Astaxanthin inhibits proliferation and induces apoptosis of human hepatocellular carcinoma 
cells via inhibition of Nf-kb P65 and Wnt/B-Catenin in vitro. Mar Drugs 13, 6064-6081.

72. Kavitha K, Kowshik J, Kishore TKK et al. (2013) Astaxanthin inhibits NF- $\kappa B$ and $\mathrm{Wnt} / \beta$-catenin signaling pathways via inactivation of Erk/MAPK and PI3K/Akt to induce intrinsic apoptosis in a hamster model of oral cancer. Biochim Biophys Acta - Gen Subj 1830, 4433-4444.

73. Chang J, Zhang Y, Li Y et al. (2018) NrF2/ARE and NF- $\kappa B$ pathway regulation may be the mechanism for lutein inhibition of human breast cancer cell. Futur Oncol 14, 719-726.

74. Jin Y, Qiu S, Shao N et al. (2018) Fucoxanthin and tumor necrosis factor-related apoptosis-inducing ligand (TRAIL) synergistically promotes apoptosis of human cervical cancer cells by targeting $\mathrm{PI} 3 \mathrm{~K} / \mathrm{Akt} / \mathrm{NF}-\mathrm{kB}$ signaling pathway. Med Sci Monit 24, 11-18.

75. Rwigemera A, Mamelona J \& Martin LJ (2015) Comparative effects between fucoxanthinol and its precursor fucoxanthin on viability and apoptosis of breast cancer cell lines MCF-7 and MDA-MB-231. Anticancer Res 35, 207-220.

76. Liu CL, Lim YP \& Hu ML (2013) Fucoxanthin enhances cisplatin-induced cytotoxicity via NFkB-mediated pathway and downregulates DNA repair gene expression in human hepatoma HepG2 cells. Mar Drugs 11, 50-66.

77. Gouranton E, Thabuis C, Riolle C et al. (2011) Lycopene inhibits proinflammatory cytokine and chemokine expression in adipose tissue. J Nutr Biochem 22, 642-648.

78. Gouranton E, Aydemir G, Reynaud E et al. (2011) Apo-10'lycopenoic acid impacts adipose tissue biology via the retinoic acid receptors. Biochim Biophys Acta - Mol Cell Biol Lipids 1811, 1105-1114.

79. Marcotorchino J, Romier B, Gouranton E et al. (2012) Lycopene attenuates LPS-induced TNF- $\alpha$ secretion in macrophages and inflammatory markers in adipocytes exposed to macrophage-conditioned media. Mol Nutr Food Res $\mathbf{5 6}$ 725-732.

80. Fenni S, Astier J, Bonnet L et al. (2019) (all-E)- and (5Z)-lycopene display similar biological effects on adipocytes. Mol Nutr Food Res 63, e1800788.

81. Fenni S, Hammou H, Astier J et al. (2017) Lycopene and tomato powder supplementation similarly inhibit high-fat diet induced obesity, inflammatory response, and associated metabolic disorders. Mol Nutr Food Res 61. doi: 10.1002/mnfr. 201601083

82. Ben-Dor A, Steiner M, Gheber L et al. (2005) Carotenoids activate the antioxidant response element transcription system. Mol Cancer Ther 4, 177-186.

83. Yu S \& Kong A-N. (2007) Targeting carcinogen metabolism by dietary cancer preventive compounds. Curr Cancer Drug Targets 7, 416-424.

84. Zhao D, Kwon SH, Chun YS et al. (2017) Anti-neuroinflammatory effects of fucoxanthin via inhibition of Akt/NF- $\kappa B$ and MAPKs/AP-1 pathways and activation of PKA/CREB pathway in lipopolysaccharide-activated BV-2 microglial cells. Neurochem Res $\mathbf{4 2}, 667-677$.

85. Rodríguez-Luna A, Avila-Roman J, Gonzalez-Rodgriguez M et al. (2018) Fucoxanthin-containing cream prevents epidermal hyperplasia and UVB-induced skin erythema in mice. Mar Drugs 16

86. Cheng F, Zhang Q, Yan FF et al. (2015) Lutein protects against ischemia/reperfusion injury in rat skeletal muscle by modulating oxidative stress and inflammation. Immunopharmacol Immunotoxicol 37, 329-334.

87. Liu T, Liu W, Zhao J et al. (2017) Lutein protects against $\beta$-amyloid peptide-induced oxidative stress in cerebrovascular endothelial cells through modulation of $\mathrm{Nrf}-2$ and NF-kb. Cell Biol Toxicol 33, 57-67.
88. Niu T, Xuan R, Jiang L et al. (2018) Astaxanthin induces the Nrf2/HO-1 antioxidant pathway in human umbilical vein endothelial cells by generating trace amounts of ROS. $J$ Agric Food Chem 66, 1551-1559.

89. Sahin K, Tuzcu M, Sahin N et al. (2010) Nrf2/HO-1 signaling pathway may be the prime target for chemoprevention of cisplatin-induced nephrotoxicity by lycopene. Food Chem Toxicol 48, 2670-2674.

90. Talvas J, Caris-Veyrat C, Guy L et al. (2010) Differential effects of lycopene consumed in tomato paste and lycopene in the form of a purified extract on target genes of cancer prostatic cells. Am J Clin Nutr 91, 1716-1724.

91. Dinkova-Kostova AT, Holtzclaw W, Cole R et al. (2002) Direct evidence that sulfhydryl groups of Keap1 are the sensors regulating induction of phase 2 enzymes that protect against carcinogens and oxidants. Proc Natl Acad Sci U S A 99, 1190811913.

92. Linnewiel K, Ernst H, Caris-Veyrat C et al. (2009) Structure activity relationship of carotenoid derivatives in activation of the electrophile/antioxidant response element transcription system. Free Radic Biol Med 47, 659-667.

93. Kiefer C, Hessel S, Lampert J et al. (2001) Identification and characterization of a mammalian enzyme catalyzing the asymmetric oxidative cleavage of provitamin A. J Biol Chem 276, 14110-14116

94. Caris-Veyrat C, Schmid A, Carail M et al. (2003) Cleavage products of lycopene produced by in vitro oxidations: characterization and mechanisms of formation. J Agric Food Chem 51, 7318-7325.

95. Lian F \& Wang XD (2008) Enzymatic metabolites of lycopene induce Nrf2-mediated expression of phase II detoxifying/ antioxidant enzymes in human bronchial epithelial cells. Int J Cancer 123, 1262-1268.

96. Böhm V, Lietz G, Olmedilla-Alonso B et al. (2020) From carotenoid intake to carotenoid blood and tissue concentrations implications for dietary intake recommendations. Nutr Rev doi: 10.1093/nutrit/nuaa008.

97. Heyman RA, Mangelsdorf D, Dyck J et al. (1992) 9-cis retinoic acid is a high affinity ligand for the retinoid $\mathrm{X}$ receptor. Cell $\mathbf{6 8}$, 397-406.

98. Mangelsdorf DJ, Borgmeyer U, Heyman R et al. (1992) Characterization of three RXR genes that mediate the action of 9-cis retinoic acid. Genes Dev 6, 329-344.

99. Petkovich M, Brand NJ, Krust A et al. (1987) A human retinoic acid receptor which belongs to the family of nuclear receptors. Nature 330, 444-450.

100. Mangelsdorf DJ, Ong ES, Dyck JA et al. (1990) Nuclear receptor that identifies a novel retinoic acid response pathway. Nature 345, 224-229.

101. Dulińska-Litewka J, Hałubiec P, Łazarczyk A et al. (2021) Recent progress in discovering the role of carotenoids and metabolites in prostatic physiology and pathology - a review - part II: carotenoids in the human studies. Antioxidants 10, 319.

102. Balmer JE \& Blomhoff R (2002) Gene expression regulation by retinoic acid. J Lipid Res 43, 1773-1808.

103. Sass JO \& Nau H (1994) Single-run analysis of isomers of retinoyl- $\beta$-D-glucuronide and retinoic acid by reversed-phase high-performance liquid chromatography. J Chromatogr A 685, 182-188.

104. Horst RL, Reinhardt T, Goff J et al. (1995) Identification of 9-cis, 13-tis-retinoic acid as a major circulating retinoid in plasma. Biochemistry 34, 1203-1209.

105. Kane MA, Chen N, Sparks S et al. (2005) Quantification of endogenous retinoic acid in limited biological samples by LC/MS/MS. Biochem J 388, 363-369. 
106. Rühl R, Krezel W \& de Lera AR (2018) 9-Cis-13,14-dihydroretinoic acid, a new endogenous mammalian ligand of retinoid $\mathrm{X}$ receptor and the active ligand of a potential new vitamin $\mathrm{A}$ category: vitamin A5. Nutr Rev 76, 929-941.

107. Krężel W, Rühl R \& de Lera AR (2019) Alternative retinoid X receptor (RXR) ligands. Mol Cell Endocrinol 491, 110436.

108. De Lera ÁR, Krezel W \& Rühl R (2016) An endogenous mammalian retinoid $\mathrm{X}$ receptor ligand, at last! Chem Med Chem 11, 1027-1037.

109. Allenby G, Bocquel M, Saunders M et al. (1993) Retinoic acid receptors and retinoid $\mathrm{X}$ receptors: interactions with endogenous retinoic acids. Proc Natl Acad Sci U S A 90, 30-34

110. Frolik CA et al. (1979) Isolation and identification of 4-hydroxy- and 4-oxoretinoic acid. In vitro metabolites of all-trans-retinoic acid in hamster trachea and liver. Biochemistry 18, 2092-2097.

111. Aydemir G, Dominguez M, De Lera A et al. (2019) Apo-14'carotenoic acid is a novel endogenous and bioactive apocarotenoid. Nutrients 11, 2084.

112. Eroglu A \& Harrison EH (2013) Carotenoid metabolism in mammals, including man: formation, occurrence, and function of apocarotenoids. J Lipid Res 54, 1719-1730.

113. Eroglu A, Hruszkewycz DP, Curley RW et al. (2010) The eccentric cleavage product of $\beta$-carotene, $\beta$-apo-13carotenone, functions as an antagonist of RXR $\alpha$. Arch Biochem Biophys 504, 11-16.

114. Suzuki T, Matsui M \& Murayama A (1995) Biological activity of (all-E)- $\beta$-apo- $12^{\prime}$-earotenoic acid and the geometrical isomers on human acute promyelocytic leukemia cell line HL-60. J Nutr Sci Vitaminol (Tokyo) 41, 575-585.

115. Sun J, Narayanasamy S, Curley RW et al. (2014) $\beta$-Apo-13carotenone regulates retinoid $\mathrm{X}$ receptor transcriptional activity through tetramerization of the receptor. $J$ Biol Chem 289, 33118-33124.

116. Narayanasamy S, Sun J, Pavlovicz R et al. (2017) Synthesis of apo-13- and apo-15-lycopenoids, cleavage products of lycopene that are retinoic acid antagonists. J Lipid Res $\mathbf{5 8}$, 1021-1029.

117. Ip BC, Liu C, Lichtenstein AH et al. (2015) Lycopene and apo-10'-lycopenoic acid have differential mechanisms of protection against hepatic steatosis in $\beta$-carotene-9', 10'- oxygenase knockout male mice. J Nutr 145, 268-276.

118. Ip BC, Hu K, Liu C et al. (2013) Lycopene metabolite, apo-10'lycopenoic acid, inhibits diethylnitrosamine-initiated, high fat diet-promoted hepatic inflammation and tumorigenesis in mice. Cancer Prev Res 6, 1304-1316.

119. Amengual J, Widjaja-Adhi $\mathrm{M}$, Rodriguez-Santiago $\mathrm{S}$ et al. (2013) Two carotenoid oxygenases contribute to mammalian provitamin A metabolism. J Biol Chem 288, 34081-34096.

120. Seña CDela, Narayanasamy S, Riedl K et al. (2013) Substrate specificity of purified recombinant human $\beta$-carotene 15,15'-oxygenase (BCO1). J Biol Chem 288, 37094-37103.

121. Dela Seña C, Sun J, Narayanasamy S et al. (2016) Substrate specificity of purified recombinant chicken $\beta$-carotene 9',10'-Oxygenase (BCO2). J Biol Chem 291, 14609-14619.

122. Yeum KJ, Dos Anjos Ferreira AL, Smith D et al. (2000) The effect of $\alpha$-tocopherol on the oxidative cleavage of $\beta$-carotene. Free Radic Biol Med 29, 105-114.

123. Tang G, Wang XD, Russell RM et al. (1991) Characterization of $\beta$-apo-13-carotenone and $\beta$-apo- 14 '-carotenal as enzymatic products of the excentric cleavage of $\beta$-carotene. Biochemistry 30, 9829-9834.

124. Moise AR, Isken A, Domiguez M et al. (2007) Specificity of zebrafish retinol saturase: formation of all-trans-13,14-dihydroretinol and all-trans-7,8- dihydroretinol. Biochemistry $\mathbf{4 6}$, 1811-1820.
125. Moise AR, Kuksa V, Imanishi Y et al. (2004) Identification of all-trans-retinol:all-trans-13,14-dihydroretinol saturase. J Biol Chem 279, 50230-50242.

126. Moise AR, Kuksa V, Blaner WS et al. (2005) Metabolism and transactivation activity of 13,14-dihydroretinoic acid. J Biol Chem 280, 27815-27825.

127. Moise AR, Alvarez S, Dominguez M et al. (2009) Activation of retinoic acid receptors by dihydroretinoids. Mol Pharmacol 76, 1228-1237.

128. Rühl R, Krezel W, de Lera A et al. (2015) 9-cis-13,14-dihydroretinoic acid is an endogenous retinoid acting as RXR ligand in mice. PLoS Genet 11, e1005213.

129. Baron JM, Heise R, Blaner W et al. (2005) Retinoic acid and its 4-oxo metabolites are functionally active in human skin cells in vitro. J Invest Dermatol 125, 143-153.

130. Chandra V, Huang P, Hamuro Y et al. (2008) Structure of the intact PPAR- $\gamma-$ RXR- $\alpha$ nuclear receptor complex on DNA. Nature 456, 350-356.

131. Mangelsdorf DJ \& Evans RM (1995) The RXR heterodimers and orphan receptors. Cell $\mathbf{8 3}, 841-850$.

132. Amengual J, Gouranton E, van Helden E et al. (2011) Betacarotene reduces body adiposity of mice via BCMO1. PLOS One 6, e20644

133. Cheng J, Miao B, Hu KQ et al. (2018) Apo-10'-lycopenoic acid inhibits cancer cell migration and angiogenesis and induces peroxisome proliferator-activated receptor $\gamma . J$ Nutr Biochem 56, 26-34.

134. Zaripheh S, Nara TY, Nakamura MT et al. (2006) Dietary lycopene downregulates carotenoid 15,15'-monooxygenase and PPAR- $\gamma$ in selected rat tissues. J Nutr 136, 932-938.

135. Chuang KH, Lee Y, Lin W et al. (2005) 9-cis-retinoic acid inhibits androgen receptor activity through activation of retinoid $\mathrm{X}$ receptor. Mol Endocrinol 19, 1200-1212.

136. Li MT, Richter F, Chang C et al. (2002) Androgen and retinoic acid interaction in LNCaP cells, effects on cell proliferation and expression of retinoic acid receptors and epidermal growth factor receptor. BMC Cancer $\mathbf{2}, 16$.

137. Richter F, Huang H, Li M et al. (1999) Retinoid and androgen regulation of cell growth, epidermal growth factor and retinoic acid receptors in normal and carcinoma rat prostate cells. $\mathrm{Mol}$ Cell Endocrinol 153, 29-38.

138. Murthy S, Marcelli M \& Weigel NL (2003) Stable expression of full length human androgen receptor in PC-3 prostate cancer cells enhances sensitivity to retinoic acid but not to 1 $\alpha, 25$-dihydroxyvitamin D3. Prostate 56, 293-304.

139. Rühl R, Fritzsche B, Vermot J et al. (2006) Regulation of expression of the retinoic acid-synthesising enzymes retinaldehyde dehydrogenases in the uteri of ovariectomised mice after treatment with oestrogen, gestagen and their combination. Reprod Fertil Dev 18, 339-345.

140. Vermot J, Fraulob V, Dolle P et al. (2000) Expression of enzymes synthesizing (aldehyde dehydrogenase 1 and retinaldehyde dehydrogenase 2 ) and metabolizing (Cyp26) retinoic acid in the mouse female reproductive system. Endocrinology 141, 3638-3645.

141. Fritzsche B, Vermot J, Neumann U et al. (2007) Regulation of expression of the retinoic acid metabolizing enzyme CYP26A1 in uteri of ovariectomized mice after treatment with ovarian steroid hormones. Mol Reprod Dev 74, 258-264.

142. Ross-Innes CS, Stark R, Holmes K et al. (2010) Cooperative interaction between retinoic acid receptor- $\alpha$ and estrogen receptor in breast cancer. Genes Dev 24, 171-182.

143. Murtaugh MA, Ma K, Benson J et al. (2004) Antioxidants, carotenoids, and risk of rectal cancer. Am J Epidemiol 159, 32-41. 
144. Ter Horst R, Van den Munckhof I, Schraa K et al. (2020) Sexspecific regulation of inflammation and metabolic syndrome in obesity. Arterioscler Thromb Vasc Biol 40, 1787-1800.

145. Mattiuzzi C \& Lippi G (2019) Current cancer epidemiology. J Epidemiol Glob Health 9, 217-222.

146. Dulińska J, Gil D, Zagajewski J et al. (2005) Different effect of beta-carotene on proliferation of prostate cancer cells. Biochim Biophys Acta - Mol Basis Dis 1740, 189-201.

147. Dulińska-Litewka J, Schmitz G, Dembińska-Kieć A et al. (2013) Is the effect of $\beta$-carotene on prostate cancer cells dependent on their androgen sensitivity? Carotenoids and vitamin A in translational medicine. in (ed. Sommerburg Olaf, Siems Werner K. K.) (Boca Raton : CRC Press, Taylor \& Francis Group). doi:10.1201/b14569-15.

148. Dawson MI \& Xia Z (2012) The retinoid X receptors and their ligands. Biochim Biophys Acta - Mol Cell Biol Lipids 1821, 21-56.

149. Rühl R (2005) Induction of PXR-mediated metabolism by $\beta$-carotene. Biochim Biophys Acta - Mol Basis Dis 1740, $162-169$.

150. Rühl R, Sczech R, Landes $\mathrm{N}$ et al. (2004) Carotenoids and their metabolites are naturally occurring activators of gene expression via the pregnane $\mathrm{X}$ receptor. Eur J Nutr $\mathbf{4 3}$, 336-343.

151. Böhm V, Lietz G, Olmedilla-Alonso B et al. (2020) From carotenoid intake to carotenoid blood and tissue concentrations implications for dietary intake recommendations. Nutr Rev doi: 10.1093/nutrit/nuaa008.

152. Cooperstone JL, Novotny J, Riedl K et al. (2018) Limited appearance of apocarotenoids is observed in plasma after consumption of tomato juices: a randomized human clinical trial. Am J Clin Nutr 108, 784-792.

153. Schmidt CK, Brouwer A \& Nau H (2003) Chromatographic analysis of endogenous retinoids in tissues and serum. Anal Biochem 315, 36-48.

154. Holzapfel NP, Holzapfel B, Champ BM et al. (2013) The potential role of lycopene for the prevention and therapy of prostate cancer: from molecular mechanisms to clinical evidence. Int J Mol Sci 14, 14620-14646.

155. Aydemir G, Kasiri Y, Bartok E et al. (2016) Lycopene supplementation restores vitamin A deficiency in mice and possesses thereby partial pro-vitamin A activity transmitted via RAR signaling. Mol Nutr Food Res 60, 2413-2420.

156. Aydemir G, Carlsen H, Blomhoff R et al. (2012) Lycopene induces retinoic acid receptor transcriptional activation in mice. Mol Nutr Food Res 56, 702-712.

157. Lim JY \& Wang XD (2020) Mechanistic understanding of $\beta$-cryptoxanthin and lycopene in cancer prevention in animal models. Biochim Biophys Acta - Mol Cell Biol Lipids 1865 158652 .

158. Ben-Dor A, Nahum A, Danilenko M et al. (2001) Effects of acyclo-retinoic acid and lycopene on activation of the retinoic acid receptor and proliferation of mammary cancer cells. Arch Biochem Biophys 391, 295-302.

159. Applegate CC, Rowles JL \& Erdman JW (2019) Can lycopene impact the androgen axis in prostate cancer?: A systematic review of cell culture and animal studies. Nutrients 11, 633.

160. Reboul E (2013) Absorption of vitamin A and carotenoids by the enterocyte: focus on transport proteins. Nutrients $\mathbf{5}$, 3563-3581.

161. Borel P, Grolier P, Mekki N et al. (1998) Low and high responders to pharmacological doses of $\beta$-carotene: proportion in the population, mechanisms involved and consequences on $\beta$ - carotene metabolism. J Lipid Res 39, $2250-2260$
162. Meléndez-Martínez AJ (2019) An overview of carotenoids, apocarotenoids, and vitamin A in agro-food, nutrition, health, and disease. Mol Nutr Food Res 63, e1801045.

163. Desmarchelier C \& Borel P (2017) Overview of carotenoid bioavailability determinants: From dietary factors to host genetic variations. Trends Food Sci Technol 69, 270-280.

164. Unlu NZ, Bohn T, Clinton SK et al. (2005) Carotenoid absorption from salad and salsa by humans is enhanced by the addition of avocado or avocado oil. JNutr 135, 431-436 (American Institute of Nutrition).

165. Riedl J, Linseisen J, Hoffmann J et al. (1999) Some dietary fibers reduce the absorption of carotenoids in women. J Nutr 129, 2170-2176.

166. Borel P, Desmarchelier C, Dumont U et al. (2016) Dietary calcium impairs tomato lycopene bioavailability in healthy humans. Br J Nutr 116, 2091-2096.

167. Biehler E, Hoffmann L, Krause E et al. (2011) Divalent minerals decrease micellarization and uptake of carotenoids and digestion products into caco-2 cells. J Nutr 141, 1769-1776.

168. Bohn T, Desmarchelier C, Dragsted C et al. (2017) Hostrelated factors explaining interindividual variability of carotenoid bioavailability and tissue concentrations in humans. Mol Nutr Food Res 611600685.

169. Wutthi-in M, Cheevadhanarak S, Yasom S et al. (2020) Gut microbiota profiles of treated metabolic syndrome patients and their relationship with metabolic health. Sci Rep 10, 10085.

170. Cheng WY, Wu CY \& Yu J (2020) The role of gut microbiota in cancer treatment: Friend or foe? Gut 69, 1867-1876.

171. Tilocca B, Pieroni L, Soggiu A et al. (2020) Gut-brain axis and neurodegeneration: state-of-the-art of meta-omics sciences for microbiota characterization. Int J Mol Sci 21, 4045.

172. Duvallet C, Gibbons SM, Gurry T et al. (2017) Meta-analysis of gut microbiome studies identifies disease-specific and shared responses. Nat Commun 8, 1784.

173. Dingeo G, Brito A, Samouda H et al. (2020) Phytochemicals as modifiers of gut microbial communities. Food Funct 11.

174. Grolier P, Borel P, Duszka C et al. (1998) The bioavailability of $\alpha$ - and $\beta$-carotene is affected by gut microflora in the rat. $\mathrm{BrJ}$ Nutr 80, 199-204.

175. Kaulmann A, André CM, Schneider YJ et al. (2016) Carotenoid and polyphenol bioaccessibility and cellular uptake from plum and cabbage varieties. Food Chem 197, 325-332.

176. Wiese M, Bashmakov Y, Chalyk N et al. (2019) Prebiotic effect of lycopene and dark chocolate on gut microbiome with systemic changes in liver metabolism, skeletal muscles and skin in moderately obese persons. Biomed Res Int 2019, 4625279.

177. Djuric Z, Bassis C, Plegue M et al. (2018) Colonic Mucosal Bacteria Are Associated with Inter-Individual Variability in Serum Carotenoid Concentrations. J Acad Nutr Diet 118, 606-616.e3.

178. Karlsson FH, Fak F, Nookaew I et al. (2012) Symptomatic atherosclerosis is associated with an altered gut metagenome. Nat Commun 3.

179. Lyu Y, Wu L, Wang F et al., Shen X \& Lin D (2018) Carotenoid supplementation and retinoic acid in immunoglobulin A regulation of the gut microbiota dysbiosis. Exp Biol Med vol. 243 613-620.

180. Liu H, Liu M, Fu X et al. (2018) Astaxanthin prevents alcoholic fatty liver disease by modulating mouse gut microbiota. Nutrients 10, 1245.

181. Wang J, Liu S, Wang H et al. (2019) Xanthophyllomyces dendrorhous-derived astaxanthin regulates lipid metabolism and gut microbiota in obese mice induced by a high-fat diet. Mar Drugs 17, 337. 
182. Amit-Romach E, Uni Z, Cheled S et al. (2009) Bacterial population and innate immunity-related genes in rat gastrointestinal tract are altered by vitamin A-deficient diet. JNutr Biochem $\mathbf{2 0}$, $70-77$.

183. Cha H-R, Chang S, Chang J et al. (2010) Downregulation of Th17 cells in the small intestine by disruption of gut flora in the absence of retinoic acid. J Immunol 184, 6799-6806.

184. Agarwal S \& Rao AV (2000) Carotenoids and chronic diseases. Drug Metab Drug Interact 17, 189-210.

185. Pandey KB \& Rizvi SI (2009) Plant polyphenols as dietary antioxidants in human health and disease. Oxid Med Cell Longev 2, 270-278.

186. Bonet ML, Ribot J, Felipe F et al. (2003) Vitamin A and the regulation of fat reserves. Cell Mol Life Sci 60, 1311-1321.

187. Bonet ML, Ribot J \& Palou A (2012) Lipid metabolism in mammalian tissues and its control by retinoic acid. Biochim Biophys Acta - Mol Cell Biol Lipids 1821 177-189.

188. Luisa Bonet M, Canas JA, Ribot J et al. (2015) Carotenoids and their conversion products in the control of adipocyte function, adiposity and obesity. Arch Biochem Biophys 572, 112-125.

189. Tourniaire F, Gouranton E, Von Lintig J et al. (2009) $\beta$ Carotene conversion products and their effects on adipose tissue. Genes Nutr 4, 179-187.

190. Landrier JF, Marcotorchino J \& Tourniaire F (2012) Lipophilic micronutrients and adipose tissue biology. Nutrients $\mathbf{4}$, 1622-1649.

191. Mounien L, Tourniaire F \& Landrier JF (2019) Anti-obesity effect of carotenoids: direct impact on adipose tissue and adipose tissue-driven indirect effects. Nutrients 11, 1562.

192. Bonet ML, Ribot J, Galmés S et al. (2020) Carotenoids and carotenoid conversion products in adipose tissue biology and obesity: pre-clinical and human studies. Biochim Biophys Acta - Mol Cell Biol Lipids 1865, 158676.

193. Kaplan LA, Lau JM \& Stein EA (1990) Carotenoid composition, concentrations, and relationships in various human organs. Clin Physiol Biochem 8, 1-10.

194. Parker RS (1989) Carotenoids in human blood and tissues. J Nutr 119, 101-104.

195. Tsutsumi C, Okuno M, Tannous L et al. (1992) Retinoids and retinoid-binding protein expression in rat adipocytes. $J$ Biol Chem 267, 1805-1810.

196. Gouranton E, Yazidi C, Cardinault N et al. (2008) Purified lowdensity lipoprotein and bovine serum albumin efficiency to internalise lycopene into adipocytes. Food Chem Toxicol 46, 3832-3836.

197. Kohlmeier L \& Kohlmeier M (1995) Adipose tissue as a medium for epidemiologic exposure assessment. Environ Health Perspect 103, 99-106 (Public Health Services, US Dept of Health and Human Services).

198. Chung HY, Ferreira A, Epstein S et al. (2009) Site-specific concentrations of carotenoids in adipose tissue: Relations with dietary and serum carotenoid concentrations in healthy adults. Am J Clin Nutr 90, 533-539.

199. El-Sohemy A, Baylin A, Kabagambe E et al. (2002) Individual carotenoid concentrations in adipose tissue and plasma as biomarkers of dietary intake. Am J Clin Nutr 76, 172-179.

200. Frey SK \& Vogel S (2011) Vitamin A metabolism and adipose tissue biology. Nutrients vol. 3 27-39.

201. Hessel S, Eichingr A, Isken A et al. (2007) CMO1 deficiency abolishes vitamin a production from $\beta$-carotene and alters lipid metabolism in mice. J Biol Chem 282, 33553-33561.

202. Kane MA, Folias AE \& Napoli JL (2008) HPLC/UV quantitation of retinal, retinol, and retinyl esters in serum and tissues. Anal Biochem 378, 71-79.
203. Kane MA, Folias AE, Wang C et al. (2008) Quantitative profiling of endogenous retinoic acid in vivo and in vitro by tandem mass spectrometry. Anal Chem 80, 1702-1708.

204. Perumal J, Sriram S, Lim HQ et al. (2016) Retinoic acid is abundantly detected in different depots of adipose tissue by SERS. Adipocyte 5, 378-383.

205. Jiang W \& Napoli JL (2012) Reorganization of cellular retinolbinding protein type 1 and lecithin:retinol acyltransferase during retinyl ester biosynthesis. Biochim Biophys Acta Gen Subj 1820, 859-869.

206. Jiang W \& Napoli JL (2013) The retinol dehydrogenase Rdh10 localizes to lipid droplets during acyl ester biosynthesis. J Biol Chem 288, 589-597.

207. Sima A, Manolescu DC \& Bhat P (2011) Retinoids and retinoidmetabolic gene expression in mouse adipose tissues. Biochem Cell Biol 89, 578-584

208. Gerhard GS, Styer A, Strodel W et al. (2014) Gene expression profiling in subcutaneous, visceral and epigastric adipose tissues of patients with extreme obesity. Int J Obes 38, 371-378.

209. Kiefer FW, Vernochet C, O'Brien P et al. (2012) Retinaldehyde dehydrogenase 1 regulates a thermogenic program in white adipose tissue. Nat Med 18, 918-925.

210. Perez-Pérez R, Ortega-Delgado F, Garcia-Santos E et al. (2009) Differential proteomics of omental and subcutaneous adipose tissue reflects their unalike biochemical and metabolic properties. J Proteome Res 8, 1682-1693.

211. Peinado JR, Jimenez-Gomez Y, Pulido M et al. (2010) The stromal-vascular fraction of adipose tissue contributes to major differences between subcutaneous and visceral fat depots. Proteomics 10, 3356-3366.

212. Bentham Science Publisher BSP (2012) Metabolic obesity: the paradox between visceral and subcutaneous fat. Curr Diabetes Rev 2, 367-373.

213. Lee MJ, Wu Y \& Fried SK (2013) Adipose tissue heterogeneity: implication of depot differences in adipose tissue for obesity complications. Mol Aspects Med 34, 1-11.

214. Krois CR, Vuckovic M, Huang P et al. (2019) RDH1 suppresses adiposity by promoting brown adipose adaptation to fasting and re-feeding. Cell Mol Life Sci 76, 2425-2447.

215. Fenzl A, Kulterer O, Spirk K et al. (2020) Intact vitamin A transport is critical for cold-mediated adipose tissue browning and thermogenesis. Mol Metab 42, 101088.

216. Felipe F, Bonet ML, Ribot J et al. (2003) Up-regulation of muscle uncoupling protein 3 gene expression in mice following high fat diet, dietary vitamin A supplementation and acute retinoic acid-treatment. Int J Obes 27, 60-69.

217. Ziouzenkova O, Orasanu O, Sharlach G et al. (2007) Retinaldehyde represses adipogenesis and diet-induced obesity. Nat Med 13, 695-702.

218. Ziouzenkova O, Orasanu O, Sukhova G et al. (2007) Asymmetric cleavage of $\beta$-carotene yields a transcriptional repressor of retinoid $\mathrm{X}$ receptor and peroxisome proliferator-activated receptor responses. Mol Endocrinol 21, 77-88.

219. Inoue $\mathrm{M}$, Tanabe $\mathrm{H}$, Matsumoto A et al. (2012) Astaxanthin functions differently as a selective peroxisome proliferatoractivated receptor $\gamma$ modulator in adipocytes and macrophages. Biochem Pharmacol 84, 692-700.

220. Xue JC, Schwarz EJ, Chawla A et al. (1996) Distinct stages in adipogenesis revealed by retinoid inhibition of differentiation after induction of PPARgamma. Mol Cell Biol 16, 1567-1575.

221. Lobo GP, Amengual J, Li H et al. (2010) $\beta, \beta$-carotene decreases peroxisome proliferator receptor $\gamma$ activity and reduces lipid storage capacity of adipocytes in a $\beta, \beta$-carotene oxygenase 1-dependent manner. J Biol Chem 285, 27891-27899. 
222. Shirakura Y, Takayanagi K, Mukai K et al. (2012) $\beta$-Cryptoxanthin suppresses the adipogenesis of 3T3-L1 cells via RAR activation. J Nutr Sci Vitaminol (Tokyo) 57, 426-431.

223. Schwarz EJ, Reginato MJ, Shao D et al. (1997) Retinoic acid blocks adipogenesis by inhibiting C/EBPbeta-mediated transcription. Mol Cell Biol 17, 1552-1561.

224. Maeda H, Hosokawa M, Sashima T et al. (2005) Fucoxanthin from edible seaweed, Undaria pinnatifida, shows antiobesity effect through UCP1 expression in white adipose tissues. Biochem Biophys Res Commun 332, 392-397.

225. Hara H, Takahashi H, Mohri S et al. (2019) $\beta$-Cryptoxanthin Induces UCP-1 Expression via a RAR Pathway in Adipose Tissue. J Agric Food Chem 67, 10595-10603.

226. Wang J, Suo Y, Zhang J et al. (2019) Lycopene supplementation attenuates western diet-induced body weight gain through increasing the expressions of thermogenic/mitochondrial functional genes and improving insulin resistance in the adipose tissue of obese mice. J Nutr Biochem 69, 63-72.

227. Mercader J, Ribot J, Murano I et al. (2006) Remodeling of white adipose tissue after retinoic acid administration in mice. Endocrinology 147, 5325-5332.

228. Tourniaire F, Musinovic H, Gouranton E et al. (2015) All-Trans retinoic acid induces oxidative phosphorylation and mitochondria biogenesis in adipocytes. J Lipid Res 56, 1100-1109.

229. Amengual J, García-Carrizo F, Arreguín A et al. (2018) Retinoic acid increases fatty acid oxidation and irisin expression in skeletal muscle cells and impacts irisin in vivo. Cell Physiol Biochem 46, 187-202.

230. Aranda A \& Pascual A (2001) Nuclear hormone receptors and gene expression. Physiol Rev 81, 1269-1304.

231. Willy PJ, Umesono K, Ong E et al. (1995) LXR, a nuclear receptor that defines a distinct retinoid response pathway. Genes Dev 9, 1033-1045.

232. Mukherjee R, Davies P, Crombie D et al. (1997) Sensitization of diabetic and obese mice to insulin by retinoid $\mathrm{X}$ receptor agonists. Nature 386, 407-410.

233. Wisse BE (2004) The inflammatory syndrome: the role of adipose tissue cytokines in metabolic disorders linked to obesity. J Am Soc Nephrol 15, 2792-2800.

234. Ouchi N, Parker JL, Lugus JJ et al. (2011) Adipokines in inflammation and metabolic disease. Nat Rev Immunol 11, 85-97.

235. Turer AT \& Scherer PE (2012) Adiponectin: mechanistic insights and clinical implications. Diabetologia 55, 2319-2326.

236. Le Lay S, Simard G, Martinez MC et al. (2014) Oxidative stress and metabolic pathologies: from an adipocentric point of view. Oxid Med Cell Longev 2014, 908539.

237. Karkeni E, Bonnet L, Astier J et al. (2017) All-trans-retinoic acid represses chemokine expression in adipocytes and adipose

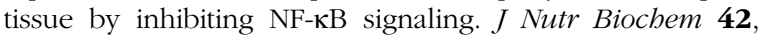
101-107.

238. Ren YR, Yang Y, Zhang R et al. (2019) MdGRF11, an apple 143-3 protein, acts as a positive regulator of drought and salt tolerance. Plant Sci 288, 110219.

239. Amengual J, Lobo GP, Golczak M et al. (2011) A mitochondrial enzyme degrades carotenoids and protects against oxidative stress. FASEB J 25, 948-959.

240. Harari A, Coster A, Jenkins A et al. (2020) Obesity and insulin resistance are inversely associated with serum and adipose tissue carotenoid concentrations in adults. J Nutr 150, 38-46.

241. Beydoun MA, Chen X, Jha K et al. (2019) Carotenoids, vitamin $\mathrm{A}$, and their association with the metabolic syndrome: a systematic review and meta-analysis. Nutr Rev 77, 32-45.

242. Östh M, Öst A, Kjolhede P et al. (2014) The concentration of $\beta$-carotene in human adipocytes, but not the whole-body adipocyte stores, is reduced in obesity. PLoS One $\mathbf{9}$, e85610.
243. Wise JA, Kaats GR, Preuss HG et al. (2009) $\beta$-Carotene and $\alpha$-tocopherol in healthy overweight adults; depletion kinetics are correlated with adiposity. Int J Food Sci Nutr 60, 65-75.

244. Liu Y, Chen H, Mu D et al. (2016) Circulating retinoic acid levels and the development of metabolic syndrome. I Clin Endocrinol Metab 101, 1686-1692.

245. Sluijs I, Beulens JWJ, Grobbee DE et al. (2009) Dietary carotenoid intake is associated with lower prevalence of metabolic syndrome in middle-aged and elderly men.J Nutr $\mathbf{1 3 9}$, 987-992.

246. Kesse-Guyot E, Ahluwalia N, Lassale C et al. (2013) Adherence to Mediterranean diet reduces the risk of metabolic syndrome: a 6-year prospective study. Nutr Metab Cardiovasc Dis 23, 677-683.

247. Canas JA, Lochrie A, McGowan A et al. (2017) Effects of mixed carotenoids on adipokines and abdominal adiposity in children: a pilot study. J Clin Endocrinol Metab 102, 1983-1990.

248. Kakutani R, Hokari S, Nishino A et al. (2018) Effect of oral paprika xanthophyll intake on abdominal fat in healthy overweight humans: a randomized, double-blind, placebocontrolled study. J Oleo Sci 67, 1149-1162.

249. Bolhassani A (2015) Cancer chemoprevention by natural carotenoids as an efficient strategy. Anticancer Agents Med Chem 15, 1026-1031.

250. Tanaka T, Shnimizu M \& Moriwaki H (2012) Cancer chemoprevention by carotenoids. Molecules 17, 3202-3242.

251. Nishino H, Murakoshi M, Ii T et al. (2002) Carotenoids in cancer chemoprevention. Cancer Metastasis Rev 21, 257-264.

252. Altucci L \& Gronemeyer H (2001) The promise of retinoids to fight against cancer. Nat Rev Cancer 1, 181-193.

253. Sun SY \& Lotan R (2002) Retinoids and their receptors in cancer development and chemoprevention. Crit Rev Oncol/ Hematol 41, 41-55.

254. Klaassen I \& Braakhuis BJM (2002) Anticancer activity and mechanism of action of retinoids in oral and pharyngeal cancer. Oral Oncol vol. 38 532-542.

255. Thompson BC, Surjana D, Halliday GM et al. (2014) Nicotinamide enhances repair of ultraviolet radiation-induced DNA damage in primary melanocytes. Exp Dermatol 23, 509-511.

256. Berry L (2016) Skin cancer. Nurs Stand 31, 15.

257. Kim IY \& He YY (2014) Ultraviolet radiation-induced non-melanoma skin cancer: regulation of DNA damage repair and inflammation. Genes Dis 1, 188-198.

258. Stahl W \& Sies H (2012) Photoprotection by dietary carotenoids: concept, mechanisms, evidence and future development. Mol Nutr Food Res 56, 287-295.

259. Balić A \& Mokos M (2019) Do we utilize our knowledge of the skin protective effects of carotenoids enough? Antioxidants 8, 259.

260. Junghans A, Sies H \& Stahl W (2001) Macular pigments lutein and zeaxanthin as blue light filters studied in liposomes. Arch Biochem Biophys 391, 160-164.

261. Armstrong BK \& Kricker A (2001) The epidemiology of UV induced skin cancer. J Photochem Photobiol B Biol 63, 8-18.

262. Thompson SC, Jolley D \& Marks R (1993) Reduction of solar keratoses by regular sunscreen use. $N$ Engl J Med 329 , $1147-1151$

263. [Ultraviolet A-induced DNA damage: role in skin cancer] PubMed. https://pubmed.ncbi.nlm.nih.gov/26263704/.

264. De Gruijl FR, Van Kranen HJ \& Mullenders LHF (2001) UV-induced DNA damage, repair, mutations and oncogenic pathways in skin cancer. J Photochem Photobiol B Biol 63, 19-27. 
265. Melnikova VO \& Ananthaswamy HN (2005) Cellular and molecular events leading to the development of skin cancer. Mutat Res - Fund Mol Mech M 571, 91-106.

266. Zhang J, Wang X, Vikash V et al. (2016) ROS and ROS-mediated cellular signaling. Oxid Med Cell Longev 2016, 4350965.

267. Paul ND \& Gwynn-Jones D (2003) Ecological roles of solar UV radiation: towards an integrated approach. Trends Ecol Evol 18, 48-55.

268. Chen L, Hu JY \& Wang SQ (2012) The role of antioxidants in photoprotection: a critical review. J Am Acad Dermatol 67, 1013-1024.

269. Silvia Díaz-Cruz M, Llorca M \& Barceló D (2008) Organic UV filters and their photodegradates, metabolites and disinfection by-products in the aquatic environment. TrAC - Trends Anal Chem 27, 873-887.

270. Serpone N, Dondi D \& Albini A (2007) Inorganic and organic UV filters: their role and efficacy in sunscreens and suncare products. Inorganica Chim Acta 360, 794-802.

271. Haywood R, Wardman P, Sanders R et al. (2003) Sunscreens inadequately protect against ultraviolet-a-induced free radicals in skin: implications for skin aging and melanoma? J Invest Dermatol 121, 862-868.

272. Demmig-Adams B \& Adams WW (2002) Food and photosynthesis: antioxidants in photosynthesis and human nutrition. Science 298, 2149-2153.

273. Poljsak B, Šuput D \& Milisav I (2013) Achieving the balance between ROS and antioxidants: when to use the synthetic antioxidants. Oxid Med Cell Longev. 2013, 956792.

274. Kruk J \& Duchnik E (2014) Oxidative stress and skin diseases: possible role of physical activity. Asian Pac J Cancer Prev 15, 561-568.

275. Commander SJ, Chang D, Fakhro A et al. (2016) Noninvasive facial rejuvenation part 1: patient-directed. Semin Plast Surg 30, 129-133.

276. Palombo P, Fabrizi G, Ruocco V et al. (2007) Beneficial longterm effects of combined oral/topical antioxidant treatment with the carotenoids lutein and zeaxanthin on human skin: a double-blind, placebo-controlled study. Skin Pharmacol Physiol 20, 199-210.

277. Stahl W, Hasan M, Farnukh A et al. (2006) in (ed. Barbara A. Gilchrest, J. K.) 113-122 (Springer New York).

278. Sies H \& Stahl W (2004) Carotenoids and UV Protection. Photochem Photobiol Sci 3, 749-752.

279. Heinrich U, Gartner C, Wiebusch M et al. (2003) Supplementation with $\beta$-carotene or a similar amount of mixed carotenoids protects humans from UV-induced erythema. J Nutr 133, 98-101.

280. Guo Q \& Packer L (2000) Ascorbate-dependent recycling of the vitamin $\mathrm{E}$ homologue Trolox by dihydrolipoate and glutathione in murine skin homogenates. Free Radic Biol Med 29, 368-374.

281. John MC, Gutteridge BH (1999) Reactive oxygen species in biological systems. in Reactive Oxygen Species in Biological Systems (ed. Springer) 189-218 (Kluwer Academic/Plenum Publishers). doi:10.1007/b113066.

282. Stocker R, Weidemann MJ \& Hunt NH (1986) Possible mechanisms responsible for the increased ascorbic acid content of Plasmodium vinckei-infected mouse erythrocytes. BBA-Gen Subj 881, 391-397.

283. Césarini JP, Michel L, Maurette JM et al. (2003) Immediate effects of UV radiation on the skin: modification by an antioxidant complex containing carotenoids. Photodermatol Photoimmunol Photomed 19, 182-189.

284. Gollnick HP, Hopfenmüller W, Hemmes C et al. (1996) Systemic beta-carotene plus topical UV-sunscreen are an optimal protection against harmful effects of natural
UV-sunlight: results of the Berlin-Eilath study. Eur J Dermatol 6, 200-205.

285. The Alpha-Tocopherol Beta Carotene Cancer Prevention Study Group (1994) The effect of vitamin e and beta carotene on the incidence of lung cancer and other cancers in male smokers. N Engl J Med 330, 1029-1035.

286. Mathews-Roth MM \& Krinsky NI (1987) Carotenoids affect development of UV-B induced skin cancer. Photochem Photobiol 46, 507-509.

287. Kirshner JR, He S, Balasubramanyam V et al. (2008) Elesclomol induces cancer cell apoptosis through oxidative stress. Mol Cancer Ther 7, 2319-2327.

288. Schafer ZT, Grassian A, Song L et al. (2009) Antioxidant and oncogene rescue of metabolic defects caused by loss of matrix attachment. Nature 461, 109-113.

289. Watson J (2013) Oxidants, antioxidants and the current incurability of metastatic cancers. Open Biol 3, 120144.

290. Rühl R, Bub A \& Watzl B (2008) Modulation of plasma all-trans retinoic acid concentrations by the consumption of carotenoid-rich vegetables. Nutrition 24, 1224-1226.

291. Persaud SD, Park S, Ishigami-Yuasa M et al. (2016) All transretinoic acid analogs promote cancer cell apoptosis through non-genomic Crabp1 mediating ERK1/2 phosphorylation. Sci Rep 6,.

292. Biesalski HK, Hemmes C, Hopfenmuller W et al. (1996) Effects of controlled exposure of sunlight on plasma and skin levels of $\beta$-carotene. Free Radic Res 24, 215-224.

293. Wang Z, Boudjelal M, Kang S et al. (1999) Ultraviolet irradiation of human skin causes functional vitamin A deficiency, preventable by all-trans retinoic acid pre-treatment. Nat Med 5, 418-422.

294. Micali G, Lacarrubba F, Dinotta F et al. (2010) Treating skin cancer with topical cream. Expert Opin Pharmacother 11, $1515-1527$.

295. Levine $N$ (1998) Role of retinoids in skin cancer treatment and prevention. J Am Acad Dermatol 39, S62-S66 (Mosby Inc.).

296. Schwartz JL, Antoniades DZ \& Zhao S (1993) Molecular and biochemical reprogramming of oncogenesis through the activity of prooxidants and antioxidants. Ann N Y Acad Sci 686, 262-278.

297. Ziegler RG (1991) Vegetables, fruits, and carotenoids and the risk of cancer. Am Clin Nutr 53, 251S-259S.

298. Peto R, Doll R, Buckley JD et al. (1981) Can dietary beta-carotene materially reduce human cancer rates? Nature 290, 201-208.

299. Brüske-Hohlfeld I (2009) Environmental and occupational risk factors for lung cancer. Methods Mol Biol 472, 3-23.

300. Van Antwerpen VL, Theron A, Richards G et al. (1995) Plasma levels of beta-carotene are inversely correlated with circulating neutrophil counts in young male cigarette smokers. Inflammation 19, 405-414.

301. Albanes D, Heinonen O, Taylor P et al. (1996) $\alpha$-Tocopherol and $\beta$-carotene supplements and lung cancer incidence in the alpha-tocopherol, beta-carotene cancer prevention study: effects of base-line characteristics and study compliance. $J$ Natl Cancer Inst 88, 1560-1570.

302. Albanes D, Heinonen O, Huttunen J et al. (1995) Effects of $\alpha$ tocopherol and $\beta$-carotene supplements on cancer incidence in the Alpha-Tocopherol Beta-Carotene Cancer Prevention Study. Am J Clin Nutr 62, 1427S-1430S.

303. Omenn G, Goodman G, Thornquist M et al. (1996) Risk factors for lung cancer and for intervention effects in CARET, the beta-carotene and retinol efficacy trial. I Natl Cancer Inst 88, 1550-1559.

304. Rapola JM, Virtamo J, Ripatti S et al. (1997) Randomised trial of $\alpha$-tocopherol and $\beta$-carotene supplements on incidence of 
major coronary events in men with previous myocardial infarction. Lancet 349, 1715-1720.

305. Hennekens CH, Buring J, Manson J et al. (1996) Lack of effect of long-term supplementation with beta carotene on the incidence of malignant neoplasms and cardiovascular disease. $N$ Engl J Med 334, 1145-1149.

306. EFSA (2006) Tolerable Upper Intake Levels Scientific Committee on Food Scientific Panel on Dietetic Products, Nutrition and Allergies. Scientific Committee on Food Scientific Panel on Dietetic Products, Nutrition and Allergies.

307. Borel P \& Desmarchelier C (2017) Genetic variations associated with vitamin A status and vitamin A bioavailability. Nutrients 9, 246.

308. Von Lintig J, Hessel S, Isken A et al. (2005) Towards a better understanding of carotenoid metabolism in animals. Biochim Biophys Acta - Mol Basis Dis 1740, 122-131.

309. Liu C, Russell RM \& Wang XD (2003) Exposing ferrets to cigarette smoke and a pharmacological dose of $\beta$-carotene supplementation enhance in vitro retinoic acid catabolism in lungs via induction of cytochrome P450 enzymes. $J$ Nutr 133, 173-179.

310. Liu C, Russell RM \& Wang XD (2004) $\alpha$-Tocopherol and ascorbic acid decrease the production of $\beta$-apo-carotenals and increase the formation of retinoids from $\beta$-carotene in the lung tissues of cigarette smoke-exposed ferrets in vitro. J Nutr 134, 426-430.

311. Erlinger TP, Guallar E, Miller ER et al. (2001) Relationship between systemic markers of inflammation and serum $\beta$-carotene levels. Arch Intern Med 161, 1903-1908.

312. Carolan BJ, Heguy A, Harvey B et al. (2006) Up-Regulation of expression of the ubiquitin carboxyl-terminal hydrolase L1 gene in human airway epithelium of cigarette smokers. Cancer Res 66, 10729-10740.

313. Harvey BG, Heguy A, Leopold P et al. (2007) Modification of gene expression of the small airway epithelium in response to cigarette smoking. J Mol Med 85, 39-53.

314. Tilley AE, Harvey B, Heguy A et al. (2009) Down-Regulation of the notch pathway in human airway epithelium in association with smoking and chronic obstructive pulmonary disease. Am J Respir Crit Care Med 179, 457-466.

315. Spira A, Beane J, Shah V et al. (2004) Effects of cigarette smoke on the human airway epithelial cell transcriptome. Proc Natl Acad Sci U S A 101, 10143-10148.

316. Yang Z -N, Davis G, Hurley T et al. (1994) Catalytic efficiency of human alcohol dehydrogenases for retinol oxidation and retinal reduction. Alcohol Clin Exp Res 18, 587-591.

317. Liu C, Russell RM \& Wang XD (2004) Low dose $\beta$-carotene supplementation of ferrets attenuates smoke-induced lung phosphorylation of JNK, p38 MAPK, and p53 proteins. J Nutr 134, 2705-2710

318. Wagner EF \& Nebreda ÁR (2009) Signal integration by JNK and p38 MAPK pathways in cancer development. Nat Rev Cancer 9, 537-549.

319. Van Helden YGJ, Godschalk R, Swarts H et al. (2011) BetaCarotene affects gene expression in lungs of male and female Bcmo1 -/- mice in opposite directions. Cell Mol Life Sci $\mathbf{6 8}$, 489-504.

320. Van Helden YGJ, Heil S, Van Schooten F et al. (2010) Knockout of the Bcmo1 gene results in an inflammatory response in female lung, which is suppressed by dietary beta-carotene. Cell Mol Life Sci 67, 2039-2056.

321. Van Helden YGJ, Godschalk R, Heil S et al. (2010) Downregulation of Fzd6 and Cthrc1 and upregulation of olfactory receptors and protocadherins by dietary beta-carotene in lungs of Bcmo1-/- mice. Carcinogenesis 31, 1329-1337.

322. Katoh M (2005) WNT/PCP signaling pathway and human cancer (Review). Oncol Rep 14, 1583-1588.
323. van Amerongen R \& Nusse R (2009) Towards an integrated view of Wnt signaling in development. Development 136, 3205-3214.

324. Jiang N, Cui YM, Liu JX et al. (2016) Multidimensional roles of collagen triple helix repeat containing 1 (CTHRC1) in Malignant cancers. J Cancer 7, 2213-2220.

325. Goodman GE, Thornquist M, Balmes J et al. (2004) The betacarotene and retinol efficacy trial: incidence of lung cancer and cardiovascular disease mortality during 6-year followup after stopping $\beta$-carotene and retinol supplements. J Natl Cancer Inst 96, 1743-1750.

326. Piga R, Van Dartel D, Bunschoten A et al. (2014) Role of Frizzled6 in the molecular mechanism of beta-carotene action in the lung. Toxicology 320, 67-73.

327. Maden M \& Hind M (2004) Retinoic acid in alveolar development, maintenance and regeneration. Philos T R Soc B: Biol Sci 359, 799-808.

328. Ventura JJ, Tenbaum S, Perdiguero E et al. (2007) p38 $\alpha$ MAP kinase is essential in lung stem and progenitor cell proliferation and differentiation. Nat Genet 39, 750-758.

329. Kim D, Kim Y \& Kim Y (2019) Effects of $\beta$-carotene on expression of selected microRNAs, histone acetylation, and DNA methylation in colon cancer stem cells. J Cancer Prev $\mathbf{2 4}$, 224-232.

330. Kim YS, Gong X, Rubin LP et al. (2019) $\beta$-Carotene 15, $15^{\prime}$-oxygenase inhibits cancer cell stemness and metastasis by regulating differentiation-related miRNAs in human neuroblastoma. J Nutr Biochem 69, 31-43.

331. Wielinga PY, Yakala GK, Heeringa P et al. (2011) Beneficial effects of alternate dietary regimen on liver inflammation, atherosclerosis and renal activation. PLoS One 6, e18432.

332. Antoni R, Johnston KL, Collins AL et al. (2017) Effects of intermittent fasting on glucose and lipid metabolism. Proc Nutr Soc 76, 361-368 (Cambridge University Press).

333. Goodrick CL, Ingram DK, Reynolds MA et al. (1990) Effects of intermittent feeding upon body weight and lifespan in inbred mice: interaction of genotype and age. Mech Ageing Dev $\mathbf{5 5}$, 69-87.

334. Speakman JR \& Mitchell SE (2011) Caloric restriction. Mol Aspects Med 32, 159-221.

335. Kahn SE, Haffner S, Heise M et al. (2006) Glycemic durability of rosiglitazone, metformin, or glyburide monotherapy. $N$ Engl J Med 355, 2427-2443.

336. Larson RS \& Tallman MS (2003) Retinoic acid syndrome: manifestations, pathogenesis, and treatment. Best Pract Res: Clin Haematol 16, 453-461.

337. Patatanian E \& Thompson DF (2008) Retinoic acid syndrome: a review. J Clin Pharm Ther 33, 331-338.

338. Loudig O, Babichuk C, White J et al. (2000) Cytochrome P450RAI(CYP26)

promoter: a distinct composite retinoic acid response element underlies the complex regulation of retinoic acid metabolism. Mol Endocrinol 14, 1483-1497.

339. Miller WH (1998) The emerging role of retinoids and retinoic acid metabolism blocking agents in the treatment of cancer. Cancer 83, 1471-1482.

340. Njar VCO, Gediya L, Purushottamachar P et al. (2006) Retinoic acid metabolism blocking agents (RAMBAs) for treatment of cancer and dermatological diseases. Bioorg Med Chem 14, 4323-4340.

341. Muindi J, Frankel S, Miller W et al. (1992) Continuous treatment with all-trans retinoic acid causes a progressive reduction in plasma drug concentrations: implications for relapse and retinoid 'resistance' in patients with acute promyelocytic leukemia. Blood 79, 299-303. 
342. Muindi JRF, Young CW \& Warrell RP (1994) Clinical pharmacology of all-trans retinoic acid. Leukemia 8, 1807-1812.

343. Peng Y -M, Dalton W, Alberts D et al. (1989) Pharmacokinetics of n-4-hydroxyphenyl-retinamide and the effect of its oral administration on plasma retinol concentrations in cancer patients. Int J Cancer 43, 22-26.

344. Altshuler DM, Gibbs R, Peltonen L et al. (2010) Integrating common and rare genetic variation in diverse human populations. Nature $\mathbf{4 6 7}, 52-58$.

345. Auton A, Abecasis G, Altshuler D et al. (2015) A global reference for human genetic variation. Nature 526, 68-74.

346. Borel P (2012) Genetic variations involved in interindividual variability in carotenoid status. Mol Nutr Food Res 56 228-240.

347. Borel P \& Desmarchelier C (2018) Bioavailability of fat-soluble vitamins and phytochemicals in humans: effects of genetic variation. Annu Rev Nutr 38, 69-96.

348. Desmarchelier C, Landrier JF \& Borel P (2018) Genetic factors involved in the bioavailability of tomato carotenoids. Curr Opin Clin Nutr Metab Care 21, 489-497.

349. Hashibe M, McKay J, Curado M et al. (2008) Multiple ADH genes are associated with upper aerodigestive cancers. Nat Genet 40, 707-709.

350. Jia M, Zhu M, Zhou F et al. (2017) Genetic variants of JNK and p38 $\alpha$ pathways and risk of non-small cell lung cancer in an Eastern Chinese population. Int J Cancer 140, 807-817.

351. Huang B, Liu B, Yang L et al. (2012) Functional genetic variants of c-Jun and their interaction with smoking and drinking increase the susceptibility to lung cancer in southern and eastern Chinese. Int J Cancer 131, E744-E758.

352. Janesick A, Wu SC \& Blumberg B (2015) Retinoic acid signaling and neuronal differentiation. Cell Mol Life Sci 72, 1559-1576.

353. Mark M, Teletin M, Vernet $N$ et al. (2015) Role of retinoic acid receptor (RAR) signaling in post-natal male germ cell differentiation. Biochim Biophys Acta - Gene Regul Mech 1849, 84-93.

354. Jiménez-Lara AM, Clarke N, Altucci L et al. (2004) Retinoicacid-induced apoptosis in leukemia cells. Trends Mol Med 10, 508-515.

355. Szondy Z, Reichert U \& Fésüs L (1998) Retinoic acids regulate apoptosis of $\mathrm{T}$ lymphocytes through an interplay between RAR and RXR receptors. Cell Death Differ 5, 4-10.

356. Dimberg A \& Öberg F (2003) Retinoic acid-induced cell cycle arrest of human of myeloid cell lines. Leuk Lymphoma $\mathbf{4 4}$, $1641-1650$

357. Bodzioch M, Dembinska-Kiec A, Hartwich J et al. (2005) The microarray expression analysis identifies BAX as a mediator of $\beta$-carotene effects on apoptosis. Nutr Cancer 51, 226-235.

358. Sacha T, Zawada M, Dulińska-Litewka J et al. (2011) BetaCarotene regulates the expression of proapoptotic BAX and CAPN2 in HL-60, U-937 and TF-1 - human acute myeloid leukemia cell lines; microarray, RQ-PCR and Western Blot analysis. Przegląd Lek 68, 258-262.

359. He Y, Gong L, Fang Y et al. (2013) The role of retinoic acid in hepatic lipid homeostasis defined by genomic binding and transcriptome profiling. BMC Genomics 14, 575.

360. Rühl R \& Landrier JF (2016) Dietary regulation of adiponectin by direct and indirect lipid activators of nuclear hormone receptors. Mol Nutr Food Res 60 175-184.

361. Mosher KI \& Schaffer DV (2018) Proliferation versus differentiation: redefining retinoic acid's role. Stem Cell Rep 10, 1673-1675.

362. Lammer EJ, Chen D, Hoar R et al. (1985) Retinoic acid embryopathy. $N$ Engl J Med 313, 837-841.
363. Ghyselinck NB \& Duester G (2019) Retinoic acid signaling pathways. Development 146, dev167502.

364. Li X, Long X, Xie Y et al. (2019) The roles of retinoic acid in the differentiation of spermatogonia and spermatogenic disorders. Clin Chim Acta. 497, 54-60.

365. Clagett-Dame M \& Knutson D (2011) Vitamin A in reproduction and development. Nutrients 3, 385-428.

366. Ghyselinck NB, Chapellier B, Calleja C et al. (2002) Genetic dissection of retinoic acid function in epidermis physiology. Ann Dermatol Venereol 129, 793-799.

367. Chapellier B, Mark M, Messaddeq N et al. (2002) Physiological and retinoid-induced proliferations of epidermis basal keratinocytes are differently controlled. EMBO J 21, 3402-3413.

368. Erkelens MN \& Mebius RE (2017) Retinoic acid and immune homeostasis: a balancing act. Trends Immunol 38, 168-180.

369. Rühl R (2007) Effects of dietary retinoids and carotenoids on immune development: Symposium on 'Nutritional influences on developmental immunology'. Proc Nutr Soc 66, 458-469.

370. Rhinn M \& Dollé P (2012) Retinoic acid signalling during development. Development 139, 843-858.

371. Huang JK, Jarjour A, Oumesmar B et al. (2011) Retinoid X receptor gamma signaling accelerates CNS remyelination. Nat Neurosci 14, 45-55.

372. Krezel W, Ghyselinck N, Samad T et al. (1998) Impaired locomotion and dopamine signaling in retinoid receptor mutant mice. Science (80-) 279, 863-867.

373. Lee LMY, Leung C, Tang W et al. (2012) A paradoxical teratogenic mechanism for retinoic acid. Proc Natl Acad Sci US A 109, 13668-13673.

374. Blaner WS (2019) Vitamin A signaling and homeostasis in obesity, diabetes, and metabolic disorders. Pharmacol Therapeut 197, 153-178.

375. Landrier JF, Kasiri E, Karkeni E et al. (2017) Reduced adiponectin expression after high-fat diet is associated with selective up-regulation of ALDH1A1 and further retinoic acid receptor signaling in adipose tissue. FASEB J 31, 203-211.

376. Petrosino JM, Disilvestro D \& Ziouzenkova O (2014) Aldehyde dehydrogenase 1A1: friend or foe to female metabolism? Nutrients 6, 950-973.

377. Mihály J, Gericke J, Lucas R et al. (2016) TSLP expression in the skin is mediated via RAR $\gamma$-RXR pathways. Immunobiology 221, 161-165.

378. Mihály J, Gamlieli A, Worn M et al. (2011) Decreased retinoid concentration and retinoid signalling pathways in human atopic dermatitis. Exp Dermatol 20, 326-330.

379. Rühl R, Hanel A, Garcia A et al. (2007) Role of vitamin A elimination or supplementation diets during postnatal development on the allergic sensitisation in mice. Mol Nutr Food Res 51, 1173-1181.

380. Stephensen CB, Rasooly R, Jiang X et al. (2002) Vitamin A enhances in vitro Th2 development via retinoid $\mathrm{X}$ receptor pathway. J Immunol 168, 4495-4503.

381. Stephensen CB, Borowsky AD \& Lloyd KCK (2007) Disruption of Rxra gene in thymocytes and Tlymphocytes modestly alters lymphocyte frequencies, proliferation, survival and Thelper type 1/type 2 balance. Immunology 121, 484-498.

382. Henning P, Conaway HH \& Lerner UH (2015) Retinoid receptors in bone and their role in bone remodeling. Front Endocrinol 6, 31.

383. Shaish A, Harari A, Hananshvili L et al. (2006) 9-cis $\beta$-carotenerich powder of the alga Dunaliella bardawil increases plasma HDL-cholesterol in fibrate-treated patients. Atherosclerosis 189, 215-221.

384. Desvergne B (2007) RXR: from partnership to leadership in metabolic regulations. Vitam Horm 75, 1-32. 
385. Szanto A, Narkar V, Shen Q et al. (2004) Review retinoid X receptors: X-ploring their (patho)physiological functions. Cell Death Differ 11, S126-S143.

386. Evans RM \& Mangelsdorf DJ (2014) Nuclear receptors, RXR, and the big bang. Cell 157, 255-266.

387. Lenhard JM (2001) PPAR $\gamma /$ RXR as a molecular target for diabetes. Recept Channels 7, 249-258.

388. Shulman AI \& Mangelsdorf DJ (2005) Retinoid X receptor heterodimers in the metabolic syndrome. $N$ Engl J Med $\mathbf{3 5 3}$, 604-615.

389. Younes M, Aquilina G, Castle L et al. (2020) COVER PAGE output category guidance date endorsed by the panel scientific guidance for the 1 preparation of applications on smoke 2 flavouring primary products 34 EFSA panel on food additives and flavourings. doi:10.2903/j.efsa.201Y.xxxx
390. Cho S, Lee D, Won C et al. (2010) Differential effects of lowdose and high-dose beta-carotene supplementation on the signs of photoaging and type I procollagen gene expression in human skin in vivo. Dermatology 221, 160-171.

391. McArdle F, Rhodes L, Parslew R et al. (2004) Effects of oral vitamin $\mathrm{E}$ and $\beta$-carotene supplementation on ultraviolet radiation-induced oxidative stress in human skin. Am J Clin Nutr 80, 1270-1275.

392. Stahl W, Heinrich U, Jungmann H et al., Sies H \& Tronnier H (2000) Carotenoids and carotenoids plus vitamin E protect against ultraviolet light-induced erythema in humans. $\mathrm{Am} \mathrm{J}$ Clin Nutr 71, 795-798.

393. Darvin ME, Fluhr J, Meinke M et al. (2011) Topical betacarotene protects against infra-red-light-induced free radicals. Exp Dermatol 20, 125-129. 